University of Nebraska - Lincoln

DigitalCommons@University of Nebraska - Lincoln

USGS Staff -- Published Research

US Geological Survey

2012

\title{
Mapping Recent Decadal Climate Variations in Precipitation and Temperature across Eastern Africa and the Sahel
}

Christopher Funk

U.S. Geological Survey, chris@geog.ucsb.edu

Joel Michaelsen

University of California, Santa Barbara, joel@geog.ucsb.edu

Michael T. Marshall

University of California, Santa Barbara

Follow this and additional works at: http://digitalcommons.unl.edu/usgsstaffpub

Part of the Geology Commons, Oceanography and Atmospheric Sciences and Meteorology Commons, Other Earth Sciences Commons, and the Other Environmental Sciences Commons

Funk, Christopher; Michaelsen, Joel; and Marshall, Michael T., "Mapping Recent Decadal Climate Variations in Precipitation and Temperature across Eastern Africa and the Sahel" (2012). USGS Staff -- Published Research. 977.

http:// digitalcommons.unl.edu/usgsstaffpub/977

This Article is brought to you for free and open access by the US Geological Survey at DigitalCommons@University of Nebraska - Lincoln. It has been accepted for inclusion in USGS Staff -- Published Research by an authorized administrator of DigitalCommons@University of Nebraska - Lincoln. 
Published in Remote Sensing of Drought: Innovative Monitoring Approaches, edited by Brian D. Wardlow, Martha C. Anderson, \& James P. Verdin (CRC Press/Taylor \& Francis, 2012).

This chapter is a U.S. government work and is not subject to copyright in the United States.

Authors:

Christopher Funk

Earth Resources Observation and Science Center

U.S. Geological Survey

Sioux Falls, South Dakota

Joel Michaelsen

Department of Geography

University of California, Santa Barbara

Santa Barbara, California

Michael T. Marshall

Department of Geography

University of California, Santa Barbara

Santa Barbara, California 


\title{
14 Mapping Recent Decadal Climate Variations in Precipitation and Temperature across Eastern Africa and the Sahel
}

\author{
Christopher Funk, Joel Michaelsen, \\ and Michael T. Marshall
}

\section{CONTENTS}

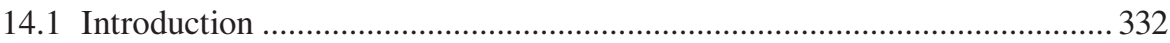

14.1.1 Mapping Decadal Variations Supports Adaptive Management ........332

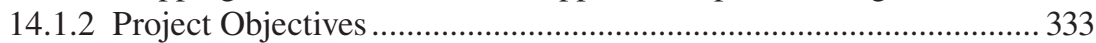

14.1.3 Relevant Previous FEWS NET Analyses ........................................ 335

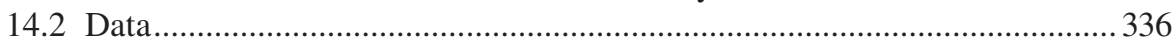

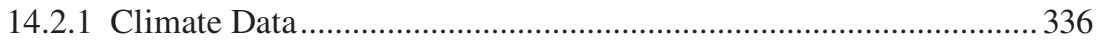

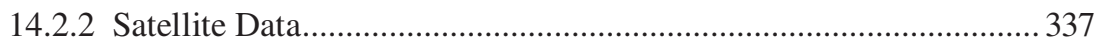

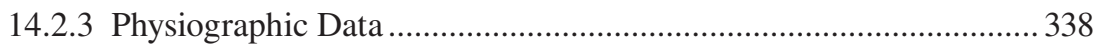

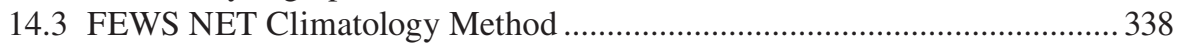

14.3.1 Examining the At-Station Trends of Temperature and Precipitation .... 340

14.3.2 Selection of Optimal Satellite and Physiographic Predictors............ 342

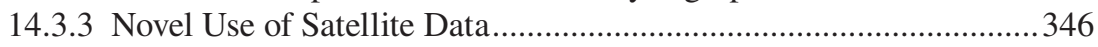

14.3.4 Cross-Validation and Model Fitting................................................... 347

14.3.5 Final Outputs: FCLIM Maps of Means and Trends ........................... 347

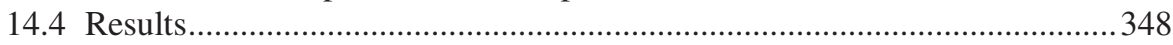

14.4.1 Local Regression Model Results .....................................................348

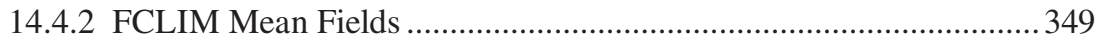

14.4.3 FEWS NET Trend Analysis Sigma Fields........................................ 350

14.4.4 FEWS NET Trend Analysis Results................................................... 351

14.4.5 FEWS NET Climate Impact Evaluations with Examples for Kenya, Ethiopia, and Sudan ............................................................. 353

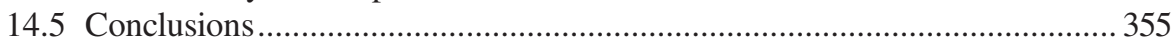

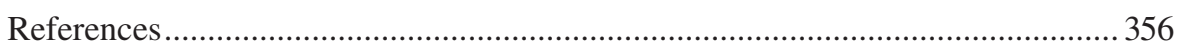




\subsection{INTRODUCTION}

This chapter presents a novel interpolation approach that combines long-term mean satellite observations, station data, and topographic fields to produce grids of climate normals and trends. The approach was developed by the Climate Hazard Group (CHG) at the University of California, Santa Barbara (UCSB), to support food security analyses for the U.S. Agency for International Development's (USAID) Famine Early Warning Systems Network (FEWS NET). The resulting FEWS NET Climatology (FCLIM) combines moving window regressions (MWRs) with geostatistical interpolation (kriging). Satellite and topographic fields often exhibit strong local correlations with in situ measurements of air temperature and rainfall. The FCLIM method uses these relationships to develop accurate and unbiased temperature and rainfall maps. The geostatistical estimation process provides standard error fields that take into account the density and spatial distribution of the point observations. These error fields are especially important when evaluating climate trends. Numerous climate change analyses present trend evaluations without assessing spatial uncertainty. In many of these studies, the number of recent observations can be very low, potentially invalidating the results. This study presents analyses for the Sahelian and eastern African rainfall and air temperatures. The results indicate significant rainfall declines in Sudan, Ethiopia, and Kenya. Every country exhibits significant increases in average air temperatures, with Sudan warming the most. This chapter concludes with a short discussion of how these results are being used to guide climate change adaptation, with a case study focused on Ethiopia.

\subsubsection{Mapping Decadal Variations Supports Adaptive Management}

Although our capabilities to monitor and mitigate seasonal fluctuations in climate are fairly well developed, our capacity to monitor and respond to decadal climate variations is much more limited. Decadal fluctuations in temperature and rainfall can be associated with recurrent drought events, sapping the resilience of rural communities and helping to reinforce a spiral of increasing poverty. Although such decadal fluctuations are the epitome of a "slow-onset disaster," they are difficult to detect for three reasons: limited observation networks, low signal-to-noise ratios, and confounding societal factors.

At present, good station observations are the ultimate foundation for detecting decadal climate anomalies. Although satellite fields and climate model output can help guide analyses, they may contain trends and shifts driven by changes in earth observing systems or model assumptions. Unfortunately, the number of weather stations is declining in Africa. Typically, there is a disjunction between "weather monitoring" and "climate monitoring" systems, with weather station data only slowly being integrated into climatological databases, making the monitoring of recent multiyear droughts difficult.

The fact that the magnitude of a multiyear drought signal is typically relatively small compared to the size of interannual variations makes decadal monitoring even harder. The shifting composition of observing networks further complicates the problem, especially in areas of mountainous terrain. A lowland station may be 
characteristically $10^{\circ}$ cooler and four times drier than a nearby highland station. Intermittent station reporting combined with interpolation of "raw" station values can create a large and completely spurious source of climate variation as low-hot-dry and high-cool-wet stations report alone or together. This problem can be addressed by interpolating station anomalies, as opposed to "raw" station values. By splitting the interpolation into two components-a long-term mean field and a seasonally varying anomaly field - the results are more accurate and less prone to contamination by changes in the spatial distribution of weather stations.

A third "detection" issue associated with multiyear droughts is the role played by societal and ecological trends. A drought arises when demand for water exceeds supply. Increasing water requirements, often associated with rapidly expanding populations and the use of water for power generation and irrigation, can lead to increasingly frequent water shortages. Similarly, land degradation and poor soil coupled with water management practices can lead to low water-use efficiencies, effectively increasing the frequency of droughts.

In order to respond effectively to climate change-whether natural or produced by greenhouse gases and aerosols - we need to develop our capacities to monitor, understand, and manage the factors related to multiyear drought. The work presented here focuses on using satellite data to map decadal climate variations. These results can support adaptive management practices and help identify emergent food security hot spots.

Although it has long been recognized that satellite data greatly improve our ability to observe drought on seasonal time scales, this chapter demonstrates the important role that remote sensing data can play in identifying trends and the emergence of new drought-prone areas exposed to a greater risk of multiyear drought events. This identification can play an important role in combating chronic poverty, malnutrition, and hunger in developing countries. Historically, most food- and water-insecure populations tend to live along the boundaries of semiarid regimes. Shifts in these boundaries can place new population groups at risks. Satellites directly observe geophysical data related to climate gradients and thus provide a valuable guide to mapping trends in climate gradients. At present, the standard climate products used to evaluate climate trends such as the Climatic Research Unit grids (New et al., $1999,2000)$ rely solely on station data and physiographic predictors such as elevation. This chapter shows that satellite observations provide a valuable addition to the climatologists' toolbox, improving our ability to monitor and respond to drought on decadal time scales.

\subsubsection{Project Objectives}

The FCLIM methodology described here provides accurate, unbiased gridded estimates of recent trends in precipitation and temperature for two critical growing seasons in the east African and Sahel regions of Africa (Figure 14.1): the March-April-May-June (MAMJ) and the June-July-August-September (JJAS) seasons. A formal geostatistical framework, incorporating estimates of how information propagates in space (the spatial variogram, which expresses spatial covariance as a measure of distance), allows us to determine standard error maps and 


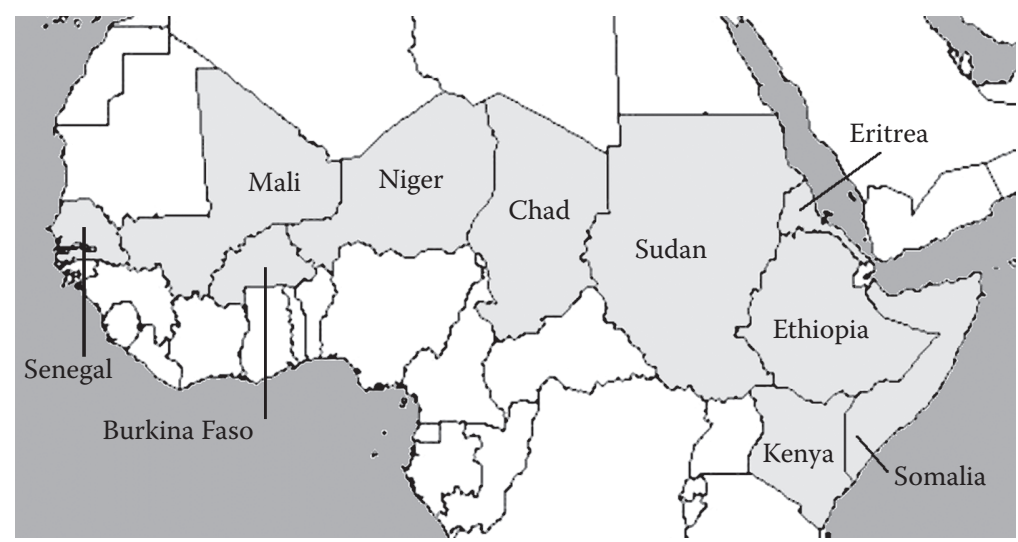

FIGURE 14.1 Map of the African countries examined in this study.

optimal estimates based on an optimal spatial interpolation technique (kriging). For the relatively dense Sahelian precipitation gauge network, the data were also mapped using an MWR technique developed by the CHG at UCSB (Funk et al., 2007). The MWR has previously been used to produce high-resolution climatologies supporting the USAID FEWS NET. The work here extends this approach to enhance precipitation trend analyses, which is important in enhancing drought monitoring capabilities. The use of long-term averages of satellite estimates of rainfall and temperature observations to guide the interpolation process is also explored. A further enhancement involves an explicit interpolation of the "at-station" trends, which facilitates estimation of uncertainties associated with the derived trend maps. Most previous analyses (including our own) have first produced a time series of monthly or seasonal rainfall and temperature grids and then analyzed trends in the resulting data layers. This can obscure uncertainties associated with the gridding process. The FEWS NET trend analysis (FTA) circumvents this problem through an explicit analysis of four season/climate variable combinations.

The MAMJ period corresponds to the critical "Long" rainy season in Kenya and the less-critical "Belg" season in Ethiopia. The JJAS period corresponds with Ethiopia's main "Meher" growing season, as well as the primary growing season across the Sahelian countries in western Africa. The Sahelian countries studied here stretch from Senegal in the west, across Mauritania, Mali, Burkina Faso, Niger, Chad, and Sudan to the nations of the Greater Horn: Eritrea, Djibouti, Ethiopia, Somalia, Kenya, Rwanda, and Burundi. Previous FEWS NET analyses have focused on downward rainfall trends in parts of the Greater Horn (primarily southern Ethiopia, central-eastern Kenya, and Somalia) (Funk et al., 2003a, 2005, 2008; Verdin et al., 2005; Williams and Funk, 2011) that suggest that the warming Indian Ocean causes hot dry air to descend across these regions, reducing MAMJ and JJAS rainfall. The work presented here updates this analysis through 2009, extends the geographic scope across the Sahel, and incorporates an additional set of observations for 100 stations provided by the Ethiopian National Meteorological Agency (NMA). 
The temperature analysis used in this study is a new component of FEWS NET climate change research. The temperature data were based solely on the Global Historical Climate Network (GHCN) station archive, quality controlled via automatic screening procedures. This temperature data set is substantially less dense than the rainfall archive, and the associated results presented here should be seen as a first attempt by FEWS NET to quantify warming trends. This work will be augmented in the future with a denser set of in situ observations.

The FTA data set consists of a set of 24 grids at $0.1^{\circ}$ resolution covering eastern Africa and the Sahel. The FTA provides sets of accurate high-resolution climatologies (FCLIM-A) together with estimates of recent climate trends (FCLIM-TR). The combination of these fields can enable us to identify emerging risk areas. While we have examined time series of seasonal rainfall totals (FCLIM-TS) in several previous papers (see Section 14.3.1), this study focuses on an explicit mapping of the rainfall and temperature trends themselves (in $\mathrm{mm}$ or ${ }^{\circ} \mathrm{C}$ per decade), along with techniques for explicitly quantifying the standard error estimates for the trend values. These standard error estimates (in $\mathrm{mm}$ or ${ }^{\circ} \mathrm{C}$ per decade), representing the geostatistical station support for a given location's trend estimate, are a unique contribution of this work to the climate change literature. Most climate change analyses evaluate trends without due regard to the impact of sparse and changing station support. We can quantify a trend's degree of certainty expressing the values in terms of standard error "sigma" values. These unitless sigma values are derived by dividing the trend estimate by the associated kriging standard errors. Kriging is a particular form of spatial interpolation that provides optimal estimates and spatial estimates of standard errors, based on the station distribution and distances. Projections of mean climate fields for the year 2025 are produced by multiplying the decadal trend estimates by five and adding the results to the 1960-1989 mean fields. Such predictions, which assume persistence of recent climate trends, certainly encompass a large, and essentially unknown, uncertainty. Nonetheless, if our analyses of the link between Indian Ocean warming and east African rainfall (Funk et al., 2008; Williams and Funk, 2011) are correct, plausible quasi-linear links exist between greenhouse gas emissions, warming in the central Indian Ocean, and reduced rainfall in southern Sudan, southern Ethiopia, Kenya, and Somalia. In any case, the decadal trend mapping approach described here should provide a useful contribution, helping us to routinely monitor and anticipate decadal climate variations.

\subsubsection{Relevant Previous FeWS net Analyses}

One focus of FEWS NET research has been the evaluation of climate change and vulnerability trends in food-insecure eastern and southern Africa. This work began with the creation of historical rainfall time series for Africa (Funk et al., 2003b; Funk and Michaelsen, 2004). In 2003, the predictive potential of early growing season rainfall in Ethiopia was evaluated and provided USAID with food balance projections (Funk et al., 2003a). This analysis revealed two disturbing tendencies. First, agriculturally critical regions of Ethiopia had experienced substantial declines in seasonal precipitation. Second, population growth/food balance analyses suggested that Ethiopia would face chronic and increasing food deficits. This study was 
followed up with a careful analysis of more than a thousand eastern African rainfall gauge observations, suggesting that a warming Indian Ocean was likely to produce increasing dryness in extremely vulnerable areas of eastern and southern Africa. Satellite observations of vegetation greenness also exhibited these declines (Funk and Brown, 2005).

More recently, Funk et al. (2008) suggested that the warming in the Indian Ocean is likely to be at least partially caused by anthropogenic greenhouse gas emissions. Thus, further rainfall declines across parts of eastern and southern Africa appear likely. For eastern Africa, these drought projections run counter to the recent fourth Intergovernmental Panel for Climate Change (IPCC) assessment. Brown and Funk (2008) argue that climate change assessments, based on inaccurate global climate precipitation fields, probably understate the global agricultural risks of the warming Pacific and Indian Oceans. The interaction of growing populations and limited potential water and cultivated areas increases food and water insecurity, amplifying the impacts of drought. Funk and Brown (2009) focused on the global risks implied by these tendencies, with the overarching view that "early warning" must embrace both the short-term opportunities provided by the timely detection of food shocks as well as an effective tracking of the slow impacts of our changing climate. Funk and Verdin (2009) used this integrated approach to document both the recent rainfall deficits and the long-term declines across eastern Kenya. More detailed climate analyses link Ethiopian and Kenyan drying to warming in the Indian Ocean and overturning circulations bringing dry hot stable air masses down across parts of the Horn of Africa (Williams and Funk, 2011).

\subsection{DATA}

The FCLIM method incorporates climate, satellite, and physiographic data using a total of 10 specific input variables (listed in Table 14.1). Following is a brief description of each variable.

\subsubsection{Climate Data}

Two dense rainfall station data sets were provided for Ethiopia and the Sahel by the Ethiopian NMA ( 100 stations) and the Centre Régional Agrhymet ( 700 stations). These stations were augmented by rainfall records from the GHCN archive and United Nations' Food and Agriculture Organization's FAOCLIM database. For average air temperature, only data from the GHCN were used. Overall, records of 1339 rainfall stations and 178 temperature stations were examined. Observations were quality controlled both via visual comparison with neighboring stations and automated screening for extreme values. This rainfall database has a station density that is an order of magnitude greater than the density found in standard station archives such as the GHCN. Note, however, that the region being examined is vast $\left(6.9\right.$ million $\mathrm{km}^{2}$, or two-thirds the size of the United States including Alaska) and the station density is still extremely low ( $\sim 1$ rainfall station for every $5,000 \mathrm{~km}^{2}$ and 1 temperature observation for every $40,000 \mathrm{~km}^{2}$ ). With data this sparse, satellite observations play a critical role in the accurate mapping of climate and climate trend gradients, literally helping to connect the dots. 
TABLE 14.1

\section{Summary of Station Observations, Satellite Fields, and Topographic Data Sets Used in This Analysis}

Data Products

Station observations

1. Seasonal rainfall $[\mathrm{mm}]$

2. Seasonal air temperature $\left[{ }^{\circ} \mathrm{C}\right]$

Satellite observations

3. MODIS land surface temperatures $\left[{ }^{\circ} \mathrm{C}\right]$

4. Meteosat infrared brightness temperatures-10th percentile $\left[{ }^{\circ} \mathrm{C}\right]$

5. Meteosat infrared brightness temperatures-90th percentile $\left[{ }^{\circ} \mathrm{C}\right]$

6. Merged rainfall estimates v. $2[\mathrm{~mm}]$

Physiographic predictors

7. Latitude $\left[{ }^{\circ}\right]$

8. Longitude $\left[{ }^{\circ}\right]$

9. Elevation $[\mathrm{m}]$

10. Slope $[\mathrm{m}$ per $\mathrm{m}]$
Acronym Dates

Sources

1960-2009 Ethiopian Nat. Met. Agency, Agrhymet, GHCN, FAO, GTS

1960-2009 GHCN

LST 2003-2009 NASA

IR10

2001-2009 NOAA/CPC

IR90

2001-2009

$\mathrm{NOAA} / \mathrm{CPC}$

RFE2

2001-2009

$\mathrm{NOAA} / \mathrm{CPC}$

USGS HYDRO1K

USGS HYDRO1K

\subsubsection{Satellite Data}

Four satellite fields were used to improve the spatial resolution and precision of the gridded climate data. The high correlations between our in situ data and these fields supported regression models to "connect the dots" of the very sparse station observations in our study site, guiding the rainfall and temperature FCLIM and the rainfall FTA modeling. The temperature gauge density was not sufficient to support the use of satellite and topographic data in the derivation of the FTA. One objective of this study was to evaluate the relative merits of these remote sensing data sets in guiding spatial interpolation and mapping drought trends. Land Surface Temperature (LST) maps at $1 \mathrm{~km}$ resolution were produced by the LST group at UCSB using thermal infrared (TIR) data collected by the Moderate Resolution Imaging Spectroradiometer (MODIS). The MODIS instruments are in polar orbit around the earth, providing day and night imagery of the earth's surface. Because the energy observed by a 
satellite depends on the temperature and emissivity of the emitting object, as well as atmospheric effects, the MODIS LST algorithm uses nighttime/daytime image pairs, observations at multiple wavelength bands $(11$ and $12 \mu \mathrm{m})$, atmospheric corrections, and radiative transfer models to estimate surface skin temperatures (Wan and Dozier, 1989). In addition to LST, TIR $(11 \mu \mathrm{m})$ brightness temperatures from geostationary Meteosat weather satellites were also used in our regression modeling. Ten years (2001-2009) of half-hourly Meteosat $\sim 0.04^{\circ}$ TIR data (Janowiak et al., 2001) were processed into seasonal images representing the warm (90th percentile) and cold (10th percentile) TIR brightness temperatures at each location. The cold 10th percentile IR maps (referred to as IR10) represent the spatial pattern of cold upper level clouds. These fields were used to guide our estimates of rainfall. The warm 90th percentile IR values (referred to as IR90) tend to isolate emissions from the earth's surface, providing gradient information related to the spatial pattern of LST values. These fields were used to guide our estimates of air temperature.

Multisatellite rainfall estimates (RFE2) from NOAA CPC (Xie and Arkin, 1997) were also used as potential guides to the FCLIM and FTA estimates. The RFE2 data set blends data from two passive microwave sensors (the Special Sensor Microwave/Imager and the Advance Microwave Sounding Unit), cold cloud duration rainfall estimates based on Meteosat TIR data (Janowiak et al., 2001), and Global Telecommunication System (GTS) rainfall values to produce daily estimates of rainfall.

\subsubsection{Physiographic Data}

Four physiographic indicators were also used as potential predictor variables for precipitation and temperature: latitude, longitude, elevation, and slope. Mean elevation and slope fields were derived on a $0.05^{\circ}$ grid by aggregating HYDRO1K elevation derivatives (Verdin and Greenlee, 1996). The four satellite fields (LST, IR10, IR90, and RFE2) were resampled to the same grid. This set of predictors allowed us to compare the performance of the traditional physiographic predictors with the newly available long-term mean fields from satellites. Traditional climatologies only use physiographic data and station observations (New et al., 1999). This study's hypothesis was that the use of satellite fields would enhance the spatial accuracy of our estimates. Although physiographic data are commonly used to guide interpolations of mean air temperature and precipitation, the link between these variables and precipitation is indirect and variable in space. High elevations and steep slopes can, on average, experience more precipitation, but this does not always hold. Presumably, satellite observations, which are much more closely related to the physics of the associated processes, would provide a better basis for spatial prediction.

\subsection{FEWS NET CLIMATOLOGY METHOD}

Several strategies have been evaluated for mapping climate fields in Africa, Asia, and central America. Early efforts focused on blending interpolated station data with output from an internal-gravity waved-based model of orographic rainfall enhancement 
(Funk et al., 2003b). Initial studies suggested that this orographic model could be successfully blended with satellite rainfall estimates (Funk et al., 2004). Extensive analysis of systematic bias within the CPC's RFE2 led to the realization that although the satellite record often struggles to correctly estimate the absolute magnitude of in situ observations, it is often very accurate in terms of representing the geographically "local" slopes of precipitation and temperature. Satellites are effective in determining areas that are relatively wet or warm from areas that are relatively dry or cool. The FCLIM uses satellite mean fields to guide the spatial interpolation of station data for point estimates of long-term means and decadal trends. This procedure has been used to guide trend analyses of Kenyan and Ethiopian rainfall (Funk et al., 2007, 2008; Funk and Verdin 2009).

In this chapter, we describe the FCLIM approach and extend its application to include long-term mean air temperature fields and precipitation trend fields. The FCLIM estimates have two major components. The first component uses MWRs (described in Section 14.3.1) to create a "first cut" estimate of the gridded field. The second component (described in Section 14.3.2) uses either kriging or a modified inverse distance weighting interpolation to create grids of regression model residuals. Cross-validation is then used to quantify the "at-station" estimation errors, while kriging standard error fields quantify the spatial uncertainty associated with the gridded FCLIM and FTA spatial predictions. In general, the FCLIM modeling process generally follows six phases:

1. Data collection. Collect and quality control all available station data.

2. Parameter estimation and visualization. Estimate the statistic of interest for the station data. Here we have used 1960-1989 historical means and 1960-2009 historical trends, but other parameters could also be used, such as medians, percentiles, or frequency. Point maps of the station means and trend values help guide the geospatial modeling of these parameters.

3. Selection of optimal satellite and physiographic predictors. Cross-validation is used with the modified inverse distance weighting (IDW) procedure to examine the fit of various parameter combinations. Visual examination of localized correlation plots (described in Section 14.3.1) can help the parameter selection process. The full output for various combinations of predictors should be examined. Prediction fields that change dramatically because of the selection of predictors are likely to indicate overfitting. Similar to typical regression applications, the FCLIM modeling process is iterative and "hands-on," guided by the modeler's expertise. As this chapter suggests, because satellite fields physically correspond directly to climate variables, they typically emerge as the best sources of predictors, and this allows the satellite-enhanced FCLIM fields to perform substantially better than traditional climate surfaces.

4. Error analysis of trend surfaces. The kriging procedure provides a measure of interpolation uncertainty based on the spatial pattern and spatial covariation of the station data. The magnitude of these standard errors can be meaningfully compared to the magnitude of the predicted trends. This is especially important in evaluating the trend fields. Given sparse data, can 
we truly make claims about trends at locations without stations? This work shows that satellite data can substantially reduce spatial prediction errors.

5. Climatic interpretation of the trend surfaces. The next phase evaluates the resulting FCLIM and FTA maps based on our understanding of the physical process and previous research. The question is, do the results appear to be plausible, given our knowledge of the climate system (mean climate, recent changes in circulation and atmospheric chemistry) and independent, corroborating data sets?

6. Interpretation and analysis of the trend surfaces. Given the mapped trends, FEWS NET scientists interpret the likely food security impacts. Such analysis depends, in part, upon the climatological means. For example, semiarid crop growing areas are more sensitive to rainfall reductions than wetter regions, because a small reduction in rainfall may substantially increase the frequency of crop failures. Areas with steep topography, and mean temperatures that change rapidly across space, may be less influenced by a $1^{\circ}$ temperature increase than are flat extremely warm regions. Underlying vulnerability, water security, and malnutrition can also exacerbate the impact of climate changes.

Section 14.2 (Data) summarized the data collection procedure. Phases two and three will be discussed in the following section and followed by a summary of phases four through six in Section 14.4 (Results).

\subsubsection{Examining the At-Station Trends of Temperature and Precipitation}

Before modeling and interpolating the data, it is worthwhile to examine trends at station locations to build confidence in the final results. Without such analysis, there is always a risk of introducing spurious "structure" into maps that does not, in fact, exist in the training data. Although sparse, the set of air temperature observations used in this study exhibits consistent increases over the period 1960-2009. Histograms of the station-based temperature trends (not shown) show that almost every station exhibited substantial temperature increases, typically ranging from $0.05^{\circ} \mathrm{C}$ to $0.5^{\circ} \mathrm{C}$ per decade. Simple averages of station data across the countries suggest that the Sudan-Niger-Mali area has experienced an increase of more than $1.0^{\circ} \mathrm{C}$ from 1969 to 2009, while the Kenya-Ethiopia area has experienced an increase of about $0.7^{\circ} \mathrm{C}$ in the same 30 year period. The magnitude of the temperature increases is equal to or greater than the interannual temporal standard deviations of the station data, averaged across the same groups of countries $\left(0.5^{\circ} \mathrm{C}\right.$ for Kenya-Ethiopia, $0.65^{\circ} \mathrm{C}$ for Sudan-Niger-Mali). Such warming can disrupt the seasonal cycle of crops, draw more water from the soil and plants - exacerbating drought conditions and reducing the amount of grain produced.

The precipitation trends tended to vary within and between countries (Figure 14.2). Dark red circles denote large recent decreases in rainfall or increases in temperature. There is fairly high level of congruence between the two seasons. In both MAMJ and JJAS, rainfall appears to be diminishing across Kenya and Ethiopia, with some smaller declines in rainfall appearing across the Sahel in JJAS. 

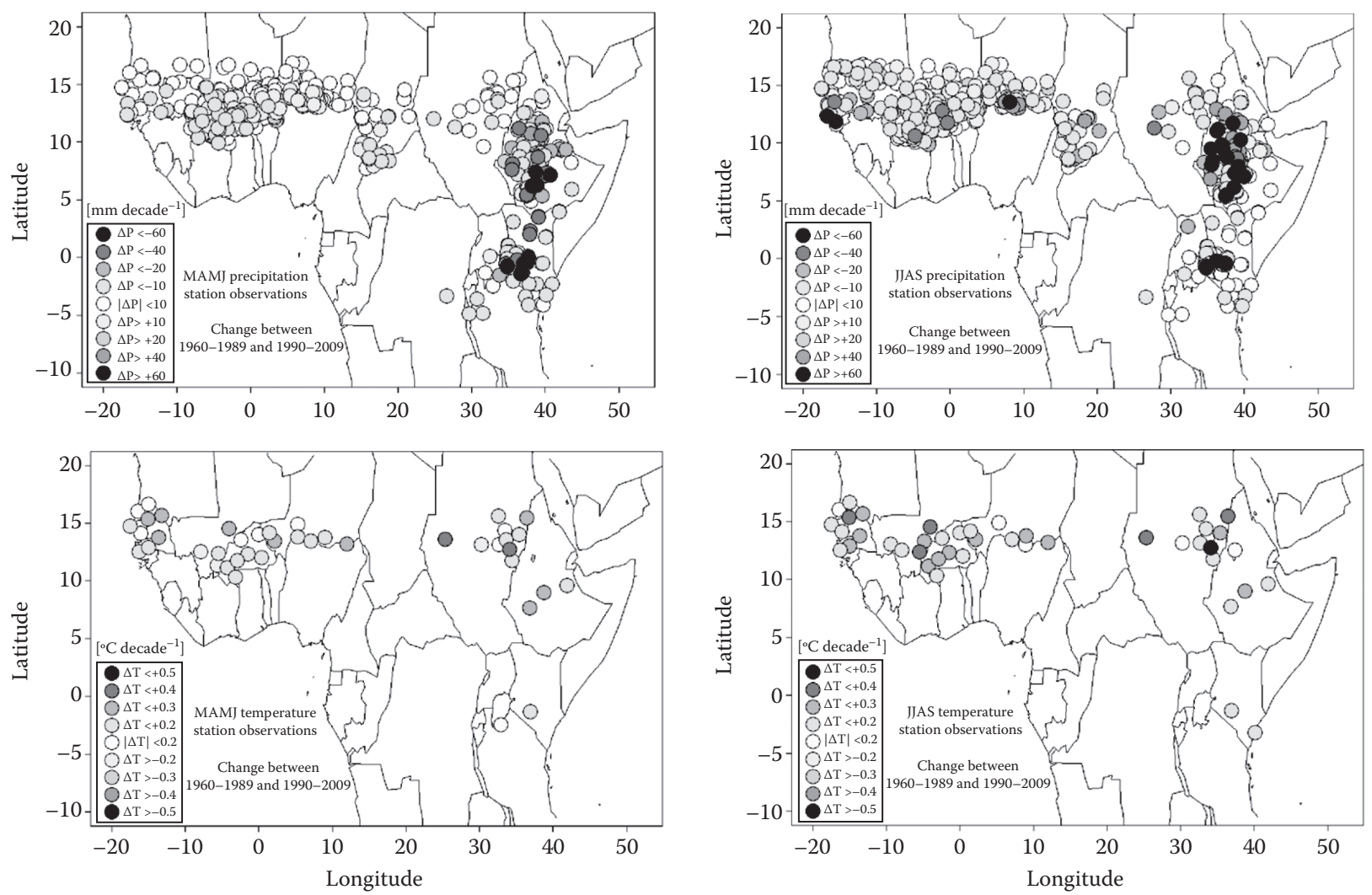

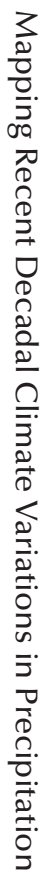

FIGURE 14.2 (See color insert.) Station observations of rainfall change (top) and temperature change (bottom) between the 1960-1989 average and the 2000-2009 average for MAMJ (left) and JJAS (right). 


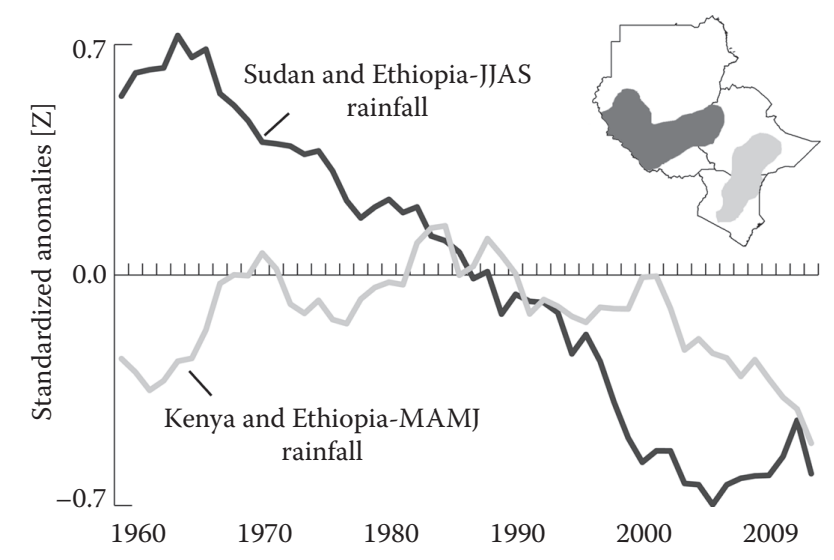

FIGURE 14.3 Time series of rainfall z-scores for two areas/seasons with declining rainfall: southern Sudan and southwestern Ethiopia during JJAS and central Kenya and southern Ethiopia during MAMJ. Time series have been smoothed with a 20 year running mean.

Since each climate observing station is essentially an independent "vote," the combined evidence suggests that significant drying has occurred in Ethiopia and Kenya. However, some stations do not exhibit downward trends in regions that appear, on average, to be drying. This could perhaps be the result of inaccurate station data or the local impact of terrain features. However, almost every temperature record shows increases in temperature over the recent era, with temperature trends ranging between $0.1{ }^{\circ} \mathrm{C}$ and $0.4^{\circ} \mathrm{C}$ per decade. Time series of interpolated rainfall data for the most affected regions of Kenya-Ethiopia (MAMJ) and Sudan-Ethiopia (JJAS) are shown in Figure 14.3, with the rainfall expressed in terms of standardized anomalies (i.e., z-scores) based on the 1960-1989 time period. Over the past 20 years, both regions have experienced large (greater than $0.5 \mathrm{Z}$ ) standardized decreases in main growing season rainfall, implying much more frequent occurrence of drought. The magnitude of the observed trends can be quite large, with the JJAS rainfall declining by more than $100 \mathrm{~mm}$ since the mid-1970s. By the year 2025, a temperature trend of $0.2^{\circ} \mathrm{C}$ per decade would be associated with a warming of $1^{\circ} \mathrm{C}$ since 1975 . By 2020 , a $50 \mathrm{~mm}$ per decade decreasing trend would be associated with a $250 \mathrm{~mm}$ decline in rainfall.

The objective in this chapter is to show how satellite data can be used to provide spatially explicit maps of these trends to complement the point-based observations, accompanied by estimates of the interpolation accuracy. To this end, a blend of MWRs and geostatistical kriging was developed.

\subsubsection{Selection of Optimal Satellite and Physiographic Predictors}

The core of the FCLIM model fitting is based on local spatial correlations between station data and satellite and physiographic predictors. At a local scale, satellite fields typically exhibit a strong spatial covariance with in situ observations, and this can be used to make accurate long-term mean and trend maps. Satellite fields also typically 


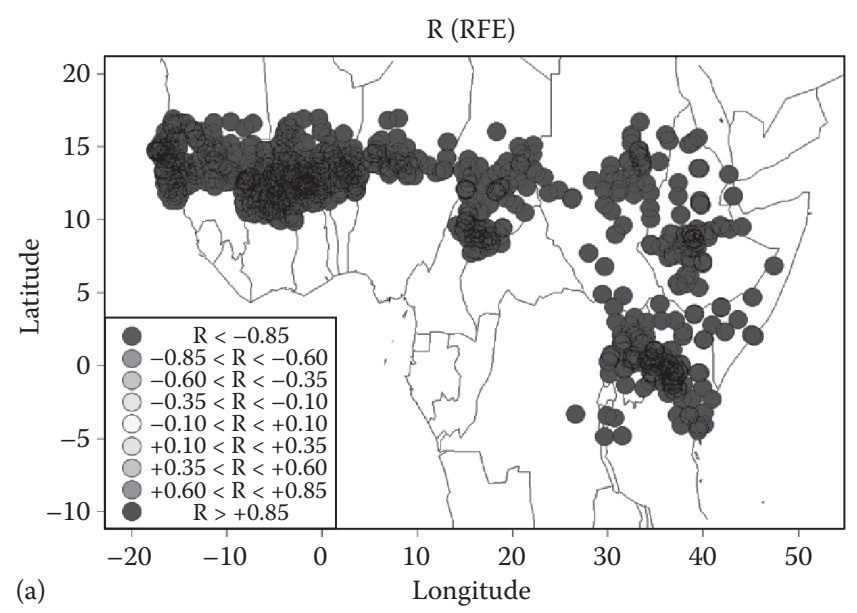

(a)

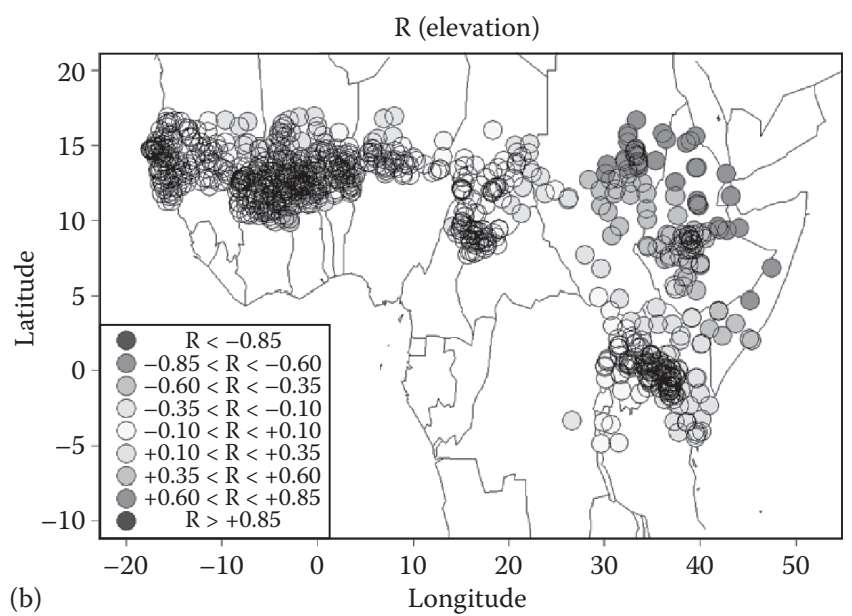

FIGURE 14.4 (See color insert.) Comparison of RFE2 and elevation correlations with JJAS precipitation normals showing the local correlation between station observations of JJAS rainfall and RFE2 means (a) and elevation (b). The median local correlation between the station means and RFE2 means was 0.91 . Local correlation computations are based on a $d_{\max }$ value of $1500 \mathrm{~km}^{2}$.

exhibit local spatial correlations that are much stronger and more consistent than physiographic fields. An example of this is shown in Figure 14.4. The Figure 14.4a shows the local correlation between 1960-1989 average JJAS precipitation and longterm (2001-2009) average JJAS RFE2 data. Despite a very complex precipitation landscape, involving steep rainfall gradients and complex orographic features, the local correlation exceeds 0.85 at every station location. In situ observations of mean rainfall are highly correlated with satellite estimates, and, thus, satellite fields can be used to guide interpolations in between station locations. This can be strongly contrasted with elevation, which forms the basis of most standard global climatologies. Station rainfall data over most of the Sahel are poorly correlated with elevation 
(Figure 14.4b). This chapter examines how spatial satellite information (Figure 14.4a) may be integrated with traditional geostatistical estimation procedures.

The idea of local correlation is central to this work. The local correlation concept is defined here and then expanded to include multivariate regression. Local correlations and regressions are defined based on a weighted function of distance, for which we use a cubic function of distance $(d)$ relative to some maximum distance $\left(d_{\max }\right)$ :

$$
\begin{aligned}
& w=0 \quad \text { if } d>d_{\max } \\
& w=\left(1-\left(\frac{d}{d_{\max }}\right)^{3}\right)^{3} \quad \text { if } d<d_{\max }
\end{aligned}
$$

For a given location, a set of observations (y) falling within a radius $d_{\max }$ is selected. Typically, y is a temporal statistic such as a long-term mean. A corresponding vector of predictors $(\mathrm{x})$ is derived by extracting pixel values at these locations; $\mathrm{x}$ is typically either a long-term average of a satellite field or a static physiographic feature (e.g., elevation). Although local spatial correlation could be calculated solely based on $\mathrm{x}$ and $\mathrm{y}$, anomalies weighted by distance were used instead. This weighting spatially focused the correlation on the target location (Equation 14.1). Anomalies at distances approaching $d_{\max }$ are forced to 0, while those located at our target center (i.e., near a station location) receive weights of 1 . Local anomalies are calculated by first estimating the local mean of $\mathrm{y}\left(\mu_{\mathrm{y}}\right)$ and $\mathrm{x}\left(\mu_{\mathrm{x}}\right)$, and then creating a centered set of spatial anomalies for the observations $\left(\mathrm{y}^{\prime}=\mathrm{y}-\mu_{\mathrm{y}}\right)$ and independent data $\left(\mathrm{x}^{\prime}=\mathrm{x}-\mu_{\mathrm{x}}\right)$ for all station locations within a radius $d_{\text {max }}$. Given a set of weights $(w)$ based on Equation 14.1, and defining “*” as the element-by-element multiplication operator, a set of weighted anomalies for $\mathrm{y}\left(\mathrm{y}_{\mathrm{w}}^{\prime}=\mathrm{w}^{*} \mathrm{y}^{\prime}\right)$ and $\mathrm{x}\left(\mathrm{x}_{\mathrm{w}}^{\prime}=\mathrm{w}^{*} \mathrm{x}^{\prime}\right)$ are generated and the local spatial correlation estimated between $\mathrm{x}^{\prime}$ and $\mathrm{y}^{\prime}$, where $\mathrm{y}^{\prime}$ represents a set of nearby station observations weighted by distance from the target center and $\mathrm{x}^{\prime}$ represents the associated predictor pixels also weighted by distance from the target center. The weighting procedure allows us to capture local variations in correlation structures, such as the positive relationships between [X = elevation] and [Y = rainfall $]$ observed in the Ethiopian highlands (Figure 14.4b).

Figure 14.4 shows the local correlation values between RFE2 and elevation (Figure 14.4b) and JJAS average 1960-1989 mean rainfall (Figure 14.4a). Similar sets of local correlations may be produced for all the candidate predictors (Table 14.1). The median correlation values between satellite/geotopographic fields and station temperature and rainfall data are shown Table 14.2. RFE2 and P10 IR data are the best predictors of mean rainfall (median $\mathrm{r} \sim 0.9$ ), and the LST and P90 fields are best predictors of average air temperatures (median $\mathrm{r} \sim 0.8$ ).

Although the results shown in Figure 14.4 and Table 14.2 were estimated at the station locations, the same procedure may be carried out on a regular grid of locations. In the full FCLIM gridding procedure, moving window correlations or regressions are estimated at each target grid cell (i.e., each $0.1^{\circ}$ cell across the maps). For clarity, this section first describes the FCLIM method using a single predictor and then expands our discussion to include a multivariate estimation procedure. 


\section{TABLE 14.2 \\ Median Cross-Validated Absolute Correlation \\ Values between Satellite/Geotopographical \\ Fields (Vertical List) and Station Data (Horizontal) for the JJAS Season}

\begin{tabular}{lcc} 
& Temperature JJAS & Rainfall JJAS \\
RFE2 & 0.74 & 0.92 \\
LST & 0.86 & 0.87 \\
P10 & 0.74 & 0.90 \\
P90 & 0.90 & 0.84 \\
Lon & 0.15 & 0.25 \\
Lat & 0.82 & 0.79 \\
Elev & 0.23 & 0.13 \\
\hline
\end{tabular}

Building on the localized correlation coefficients, we can create a local estimate of $\mathbf{y}$ based on $\mathrm{x}\left(\mathrm{y}_{\mathrm{est}}\right)$ :

$$
\mathrm{y}_{\mathrm{est}}=\mu_{\mathrm{y}}+\mathrm{r}_{1}\left(\mathrm{x}_{\mathrm{w}}^{\prime}, \mathrm{y}_{\mathrm{w}}^{\prime}\right) \sigma_{\mathrm{y}} \sigma_{\mathrm{x}}^{-1}
$$

where

$\mu_{\mathrm{y}}$ is the local mean of $\mathrm{y}$

$\sigma_{y}$ is the local standard deviation of the stations

$\sigma_{x}$ is the local standard deviation of the predictors

$\mathrm{r}_{\mathrm{l}}\left(\mathrm{x}_{\mathrm{w}}^{\prime}, \mathrm{y}_{\mathrm{w}}^{\prime}\right)$ is the local correlation as described earlier

In practice, a more complicated relationship between $\mathrm{x}$ and $\mathrm{y}$ can be used, based on transforms of the data and/or a nonlinear (typically spline-based) estimator. These transforms were not used here because of the large spatial domain analyzed and the spatial nonstationarity of distributions and relationships across the region. MWR estimates are typically produced for every grid cell. Each station value is then paired with the closest grid cell, and residuals are estimated. A model semivariogram may then be fit to the residuals and a geostatistical interpolation technique (kriging) used to produce a grid of residual values. Because the model semivariogram explicitly quantifies the spatial decorrelation with increasing distance, kriging produces spatial maps of standard error, contingent on the spatial distribution of the observation network. The MWR and residual fields are summed, creating an estimate that combines correlated independent predictors and the spatial covariance of the in situ observations themselves. The estimate is calculated as

$$
\mathrm{FCLIM}=\mathrm{y}_{\text {est }}+\mathrm{k}
$$

where $\mathrm{k}$ represents the interpolated residuals from our local regression. The estimates that are produced are referred to as FCLIM values. 
The FCLIM methodology, which comprises Equations 14.1 through 14.3, uses the information in the station data in three ways. First, a local mean $\left(\mu_{\mathrm{y}}\right)$, centered at location 1, approximates the general magnitude of our estimated value. The local relationship between $\mathrm{y}$ and $\mathrm{x}$ is then used to further refine our estimate (in Equation 14.2), taking advantage of any local correlation between y and x. Finally, we include an interpolation step (Equation 14.3), which incorporates the values at the stations and adds fine resolution information to our results. Areas near observing sites will be adjusted toward the in situ values.

\subsubsection{Novel Use of Satellite Data}

In practice, the FCLIM methodology is typically invoked using a multivariate set of predictors, potentially including both physiographic variables (latitude, longitude, elevation, and slope) and satellite observations of rainfall, infrared brightness temperatures, and LST (Table 14.3). Instead of focusing on ability of these data sets to represent temporal variations in weather, the FCLIM approach focuses on the ability of these variables to represent spatial gradients of temperature and precipitation.

The FCLIM approach involves exploratory analysis and selection of a relatively small number (typically 4-6) of predictors and the identification of a characteristic scale $\left(d_{\max }\right)$ determined primarily by station density. For each location 1, a matrix of

\section{TABLE 14.3}

\section{Local Regression Models and Cross-Validated Skill Estimates}

\begin{tabular}{|c|c|c|c|c|c|}
\hline & Width [km] & $\begin{array}{l}\text { Number } \\
\text { of Stations }\end{array}$ & Regression $\mathbf{R}^{2}$ & $\begin{array}{c}\text { Regression } \\
\text { Standard } \\
\text { Error }\end{array}$ & Predictors \\
\hline $\begin{array}{l}\text { MAMJ 1960-1989 } \\
\text { temperature }\end{array}$ & 2000 & 111 & 0.95 & $1.0^{\circ} \mathrm{C}$ & $\begin{array}{l}\text { Lon, lat, elev, } \\
\text { LST, P90 }\end{array}$ \\
\hline Temperature trends & & 57 & 0.00 & $0.13^{\circ} \mathrm{C}$ & \\
\hline $\begin{array}{l}\text { JJAS 1960-1989 } \\
\text { temperature }\end{array}$ & 2000 & 113 & 0.92 & $1.2^{\circ} \mathrm{C}$ & $\begin{array}{l}\text { Lon, lat, elev, } \\
\text { LST, P90 }\end{array}$ \\
\hline Temperature trends & & 56 & 0.07 & $0.13^{\circ} \mathrm{C}$ & \\
\hline $\begin{array}{l}\text { MAMJ 1960-1989 } \\
\text { rainfall }\end{array}$ & 1500 & 894 & 0.88 & $68 \mathrm{~mm}$ & $\begin{array}{l}\text { Lon, lat, elev, } \\
\text { RFE2, LST, } \\
\text { P10, P90 }\end{array}$ \\
\hline Rainfall trends & & 536 & 0.34 & $13 \mathrm{~mm}$ & $\begin{array}{l}\text { Lon, lat, elev, } \\
\text { LST, P10, } \\
\text { P90 }\end{array}$ \\
\hline $\begin{array}{l}\text { JJAS 1960-1989 } \\
\text { rainfall }\end{array}$ & 1500 & 960 & 0.93 & $72 \mathrm{~mm}$ & $\begin{array}{l}\text { Lon, lat, elev, } \\
\text { RFE2, LST, } \\
\text { P10, P90 }\end{array}$ \\
\hline Rainfall trends & & 587 & 0.22 & $21 \mathrm{~mm}$ & $\begin{array}{l}\text { Lon, lat, elev, } \\
\text { LST, P10, } \\
\text { P90 }\end{array}$ \\
\hline
\end{tabular}


centered predictors $\left(x_{w}^{\prime}\right)$ and a vector of observed values $\left(y_{w}^{\prime}\right)$ can be used to identify a local multivariate regression using

$$
y_{e s t}=b_{o}+b^{T} x_{w}^{\prime}
$$

Again, either IDW or geostatistical kriging can be used to interpolate the residuals. At each grid location, the final FCLIM estimate combines the local regression intercept $\left(b_{o}\right)$, a vector of local regression slope values $(b)$, a vector of local gridded satellite and physiographic predictors $(x)$, and a local estimate of the kriged residuals $(k)$ :

$$
\text { FCLIM }=b_{o}+b^{T} x+k
$$

Comparisons of kriging and IDW suggest similar levels of accuracies. In this work, IDW is used with automated cross-validation procedures to assess accuracy, and geostatistical kriging is applied within the final analyses. The kriging procedure produces maps of expected standard error.

\subsubsection{Cross-Validation and Model Fitting}

As with any regression procedure, model fitting is an important part of the modeling procedure. This can be especially true when working with spatially correlated data, which is the typical case when working with geographic information. To address this need, the FCLIM process uses interactive visualization of correlations (see Figure 14.4), cross-validation, and both visual and statistical evaluation of the resulting output fields. As with other regression techniques, FCLIM can be automated, but works best when expert analysts guide the procedure. A 10 -fold cross-validation technique is used where $10 \%$ of the station data are withheld for validation and the remaining $90 \%$ of the data used to fit the full FCLIM model. This process is repeated 10 times to produce a robust estimate of the model accuracy. Cross-validation and examination of the gridded output fields is used to identify successful model combinations.

\subsubsection{Final Outputs: FClim Maps of Means and Trends}

The full FCLIM procedure, which includes the MWR and kriging, was used to model the MAMJ and JJAS temperature and precipitation 1960-1989 station averages. The resulting FCLIM-average fields are unique in that they use satellite data to help guide the interpolation of long-term mean station data. Another novel aspect of this work is the explicit FCLIM mapping of the station-based precipitation trend estimates (FCLIM-TR). Most trend analyses tend to interpolate station observations and then evaluate low frequency variations in the gridded data. This approach makes it difficult to accurately assess the implications of sparse and changing observation networks. This new approach applies the multivariate FCLIM methodology (Equations 14.3 and 14.4) directly to station-based estimates of trends for MAMJ and JJAS rainfall. The air temperature network was not sufficiently dense to support 
this level of detailed analysis, and the at-station trends were interpolated using kriging. The kriging procedure explicitly defines the spatial variation of the interpolated information; this produces maps of the associated standard errors. This allows us to say that at location 1 , the trend has most likely been $y_{\text {est }}$, with a $95 \%$ confidence interval of $\pm 1.96 \sigma_{y_{\text {est }}}$. It is important to note, however, that there are many types of uncertainty not encapsulated here related to measurement errors and the fundamental nonstationarity of the climate itself, which is likely the most important. Despite these remaining uncertainties, the maps presented in this study, when used together, can assist in identifying emerging climate patterns that necessitate rapid response and adaptation strategies.

In addition to the core data products, eight other products are provided through the FCLIM methodology: four "sigma" fields and four "future climate" fields. The four sigma fields represent the ratio of the estimated trends and standard errors, which allow the relative magnitude of the trends to be compared to the spatial interpolation uncertainty. Areas with sigma values having absolute values of greater than 2 can be considered as quite reliable. Another four fields are derived by multiplying the decadal trend maps by 5 and adding the result to the 1960-1979 mean fields. These maps depict 2025 climate surfaces, assuming recent trends persist. Such maps are extremely useful for analyzing the drought implications of rainfall trends. For example, many crops require a certain minimum seasonal rainfall total, and the 2025 projections can help identify areas where specific types of agriculture may no longer be viable in the future. This information can then help guide adaptation efforts. A specific example of this type of analysis is given in Section 14.4.5, where the spatial drought implications of the observed drying trends (shown in Figures 14.2 and 14.3) are evaluated.

\subsection{RESULTS}

\subsubsection{Local Regression Model Results}

Cross-validation and model exploration led to the selection of localized regression models for all four long-term mean fields and the two rainfall trend surfaces (Table 14.3). The dense rainfall gauge network supported complex regression models that performed very well for long-term mean fields $\left(\mathrm{R}^{2} \approx 0.9\right)$. While variance explained for the rainfall trends was substantially lower $\left(\mathrm{R}^{2} \approx 0.3\right)$, the regression models still reduced the overall interpolation errors. These models also provided some guidance in areas devoid of station observations. The long-term mean temperature values were fit very well $\left(\mathrm{R}^{2} \geq 0.9\right)$. For the sparse set of temperature trend observations, cross-validation analysis suggested that the combination of regression and interpolation models performed similarly to either regression or interpolation models alone. The very low density of observing sites did a poor job of restraining the regression model results, and the selection of different predictor variables created substantially different temperature trend maps. Parsimony led us, therefore, to simply adopt the interpolation model for this component. Future research, with a more complete climate record, should lead to a more sophisticated analysis and spatially complex picture of recent temperature trends. 


\subsubsection{FCLIM MeAN FieLdS}

Figure 14.5 shows the four FCLIM mean fields for the 1960-1989 period. This time period was chosen because these decades had the highest station density of rainfall and temperature observations. It is worth pausing to consider the spatial structure of the climate data displayed, as this will inform our discussion of the observed rainfall and temperature trends. In MAMJ, the region is generally dry, except for a "butterfly" pattern of higher rainfall in Kenya, spanning the shore of Lake Victoria and the central highlands, and along the southern escarpment of Ethiopian highlands.
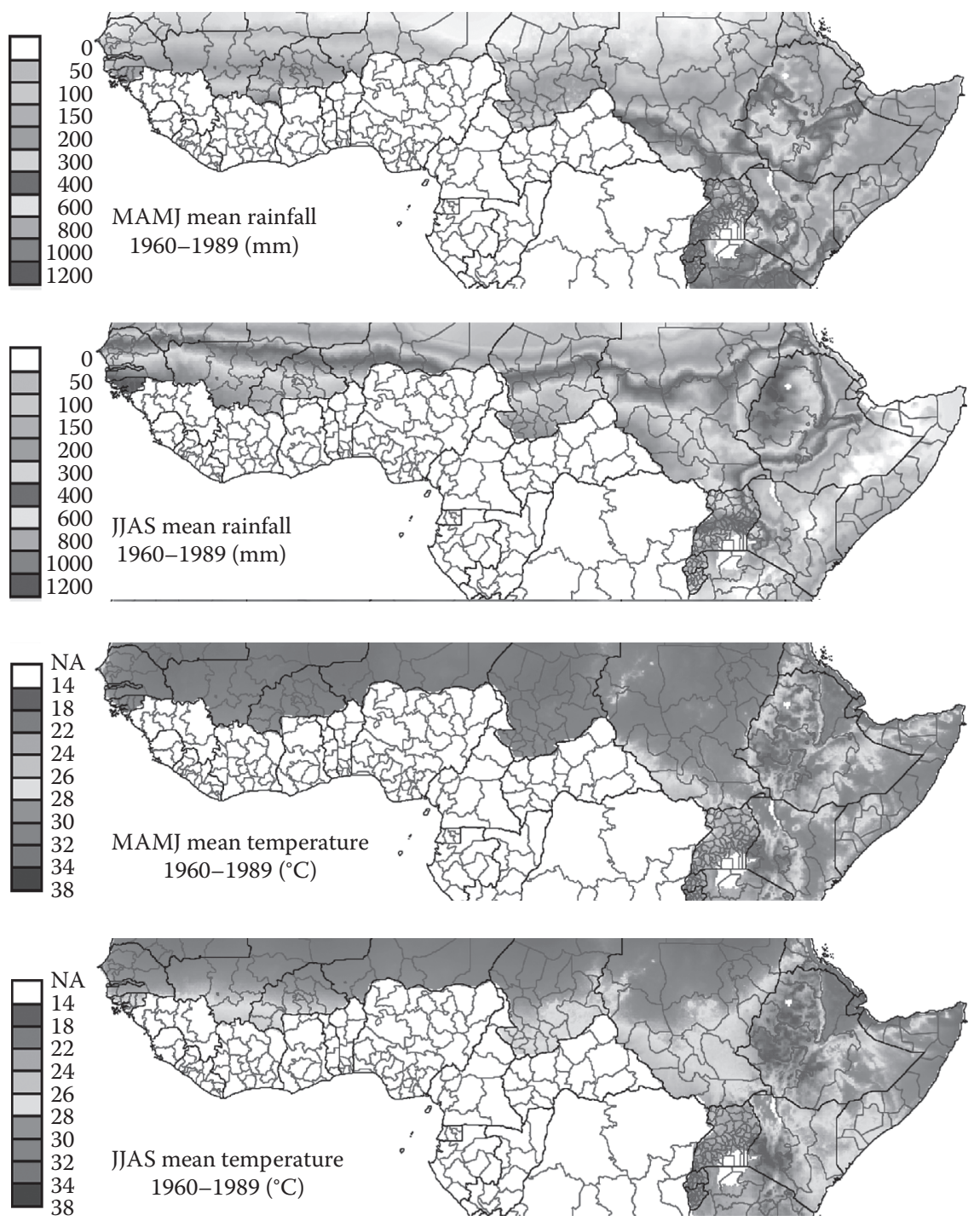

FIGURE 14.5 (See color insert.) FCLIM maps for average 1960-1989 seasonal rainfall and air temperature for the MAMJ and JJAS seasons. 
These rains support the important Long and Belg cropping seasons in these countries. These regions also show up as cool islands in two mean temperature maps, with air temperatures of less than $24^{\circ} \mathrm{C}$. These cool temperatures not only help reduce potential evaporation but also slow the maturation cycle of the crops, lengthening the required growing period. These long maturation periods can boost the accumulation of biomass but may also increase exposure to drought, since a long period of adequate crop water supply is required to produce optimal growing conditions. During JJAS, the intertropical front establishes itself north of the equator, and the Sahel receives most of its rains. Across the Sahel, temperatures decline between MAMJ and JJAS but still remain warm. A strong north-south temperature gradient appears during the JJAS period, with the southern edges of the Sahelian countries receiving the most rainfall and coolest air temperatures. A similar structure exists in the JJAS rainfall climatology, with the Sahel exhibiting very strong rainfall gradients. Exceptions to the latitudinal gradients in JJAS rainfall and temperature fields occur in Sudan and Ethiopia, where high mountains produce cooler, wetter conditions.

\subsubsection{FeWS Net Trend Analysis Sigma Fields}

When evaluating climate trends, two primary factors should be considered concerning (1) the magnitude of the observed trends and (2) the magnitude of the estimated trends relative to the underlying uncertainty of the interpolated fields. The latter factor is almost never considered and can often be obfuscated by the analysis of interpolated monthly or seasonal data. One simple way to evaluate these two components (trend magnitude and uncertainty) is to divide the interpolated trend fields by the standard error in the interpolation. The resulting unitless sigma images retain the sign of the underlying trend fields but are now expressed in units of standard errors (Figure 14.6). Values of 1,2, and 3 correspond to the $85 \%, 98 \%$, and $99.9 \%$ confidence levels, respectively, signifying the trend is statistically significant. Most regions covered in this analysis had sigma values with absolute values of greater than 2 ; thus, the signal-to-noise ratio for the trend analysis is high and our confidence in the spatial accuracy of the results high. This is surprising considering that the associated station densities were on the order of $\sim 1$ rainfall station every $5,000 \mathrm{~km}^{2}$ and 1 temperature observing site every $40,000 \mathrm{~km}^{2}$. The appropriate use of satellite fields helped achieve this result, reducing the geospatial random error and improving the signal-to-noise ratios. Note that other trend analysis products, such as those provided by the Climatic Research Unit (New et al., 1999, 2000), do not quantify the spatial uncertainty of trend estimates.

However, the sigma maps do not fully characterize all the sources of uncertainty. Undetected problems in the station observations and sampling uncertainties in the trend estimates are two unaccounted sources of uncertainty. Note also that the trend (and associated error) estimates are for areal averages and not point estimates. Some stations in "trend" areas will not exhibit trends, as shown by the station data in Figure 14.2. Based on these caveats, the sigma fields shown in Figure 14.6 suggest that the resulting trend analyses can be accepted with a high degree of confidence, either because of the high density of observations and reasonable levels of predictability in the rainfall trends, or because the trend signal is coherent (everywhere positive) and the spatial covariance pattern of the warming trends is relatively simple. 

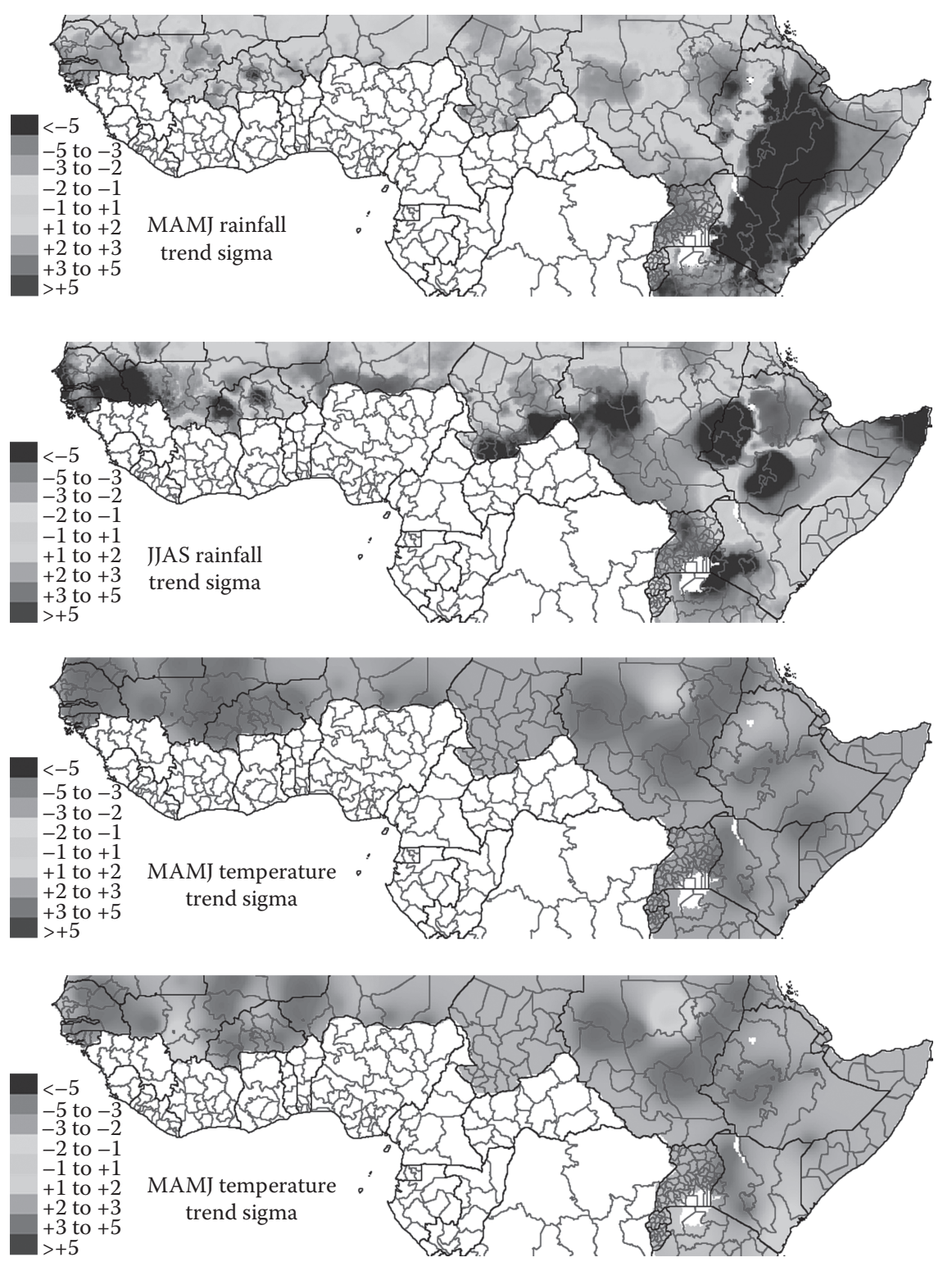

FIGURE 14.6 (See color insert.) Rainfall and temperature sigma fields. Sigma values are the estimated trend fields divided by the interpolation standard error.

\subsubsection{FEWS Net Trend Analysis Results}

Figure 14.7 shows the FTA maps for MAMJ and JJAS rainfall and air temperatures. For MAMJ rainfall, substantial rainfall declines (exceeding $20 \mathrm{~mm}$ per decade) are identified in central Kenya and south-central Ethiopia. A $-20 \mathrm{~mm}$ per decade decline, between the 1960-1989 era and 2025, would be consistent with an overall 

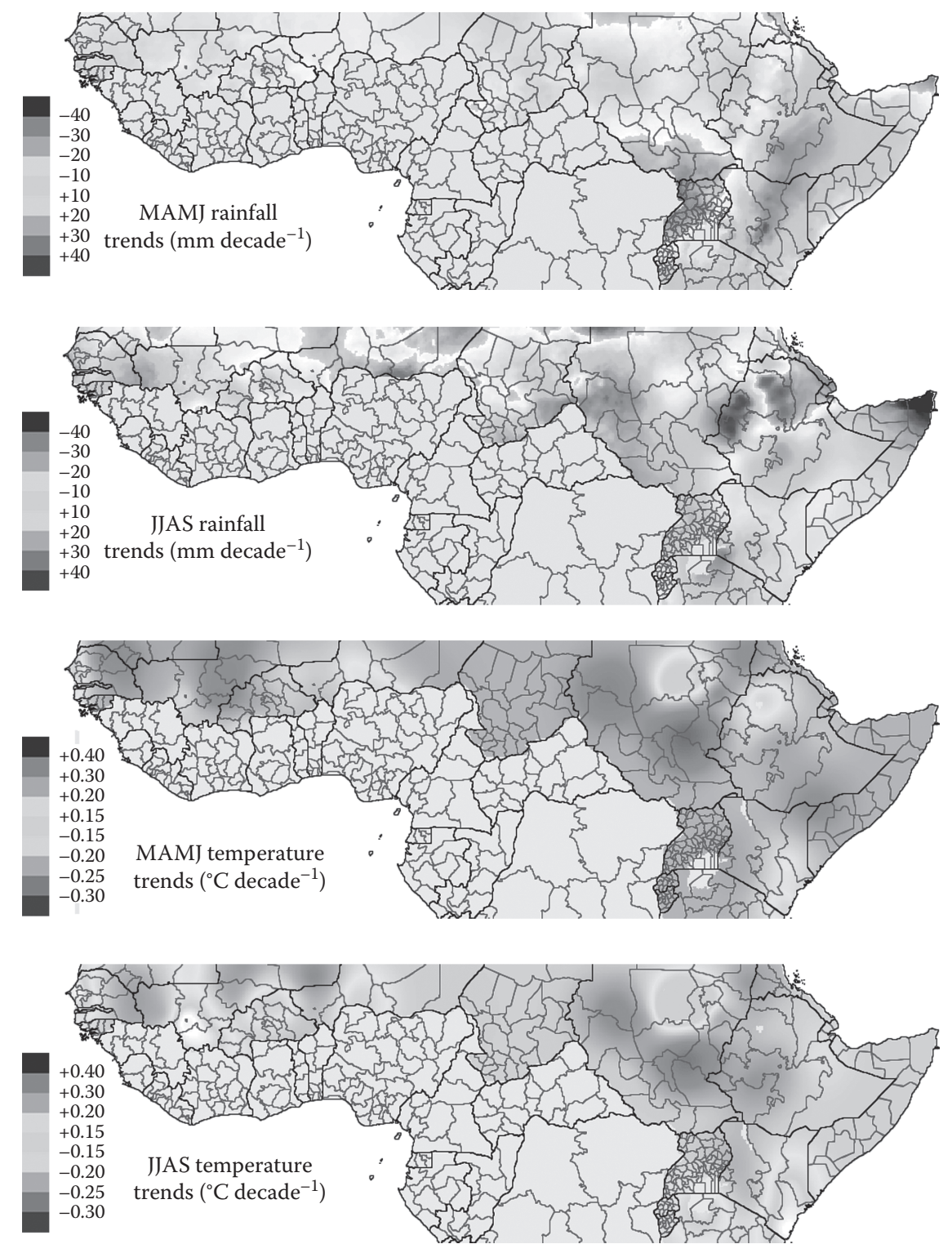

FIGURE 14.7 (See color insert.) The 1960-2009 rainfall and trend maps for MAMJ and JJAS.

rainfall reduction of $-100 \mathrm{~mm}$. In areas receiving an average of $400-600 \mathrm{~mm}$ of rainfall, this corresponds to a $17 \%-25 \%$ reduction in main growing seasonal rainfall. The station density in Ethiopia and Kenya is high, and the sigma fields for these regions are very low (often less than -7). As a result, the certainty surrounding these declines is high, and the potential impacts to the Ethiopian Belg and Kenyan 
Long rain growing seasons are serious. The spatial pattern of JJAS rainfall trends is more complicated. Pockets of rainfall reduction appear near the border of Senegal and Mali, as well as southern Chad and Sudan. This drying is likely linked to drying in southwestern Ethiopia and appears to be accompanied by rainfall increases in northwestern Ethiopia. For southern Ethiopia and southern Sudan, the impact of these rainfall declines could be quite problematic, since they correspond with areas of fairly high population density. This will be discussed further in Section 14.4.5. Additional drying tendencies are observed over northern Somalia and parts of Uganda. Enhanced rainfall is observed over central Niger.

The MAMJ and JJAS temperature trends show values ranging from near zero to more than $0.4^{\circ} \mathrm{C}$ per decade. In general, the warming during the warmer MAMJ season is slightly greater than JJAS (Figure 14.7). Both the MAMJ and the JJAS warming trend exhibit similar east-west patterns. Warming is generally greater in Senegal-Mali and southern Sudan-Ethiopia than in Niger and northern Sudan and Ethiopia. The warming patterns tend to mirror the inverse of the rainfall trends. In some of the areas, the magnitude of the decadal temperature trends (up to $0.4^{\circ} \mathrm{C}$ per decade) approaches the interannual air temperature standard deviation and thus indicates large changes in climate.

\subsubsection{FeWS Net Climate Impact Evaluations with Examples for KenYa, Ethiopia, and Sudan}

Whether related to natural internal variations of the climate system or anthropogenic actions related to greenhouse gas emissions, low frequency climate trends can have serious impacts on food-insecure nations. To support the information needs of food security and development specialists, FEWS NET/USGS has created a new series of reports, Informing Climate Change Adaptation. These reports discuss the food security and climate adaptation implications of trend analyses, such as those presented in Figure 14.4, with the goal of better guiding development and disaster mitigation activities. These reports are disseminated through the USGS FEWS NET portal (http://earlywarning. usgs.gov/fews/reports.php). In previous research, we have suggested that the drying in parts of eastern Africa, Kenya, and Sudan is related to an $\sim 1^{\circ} \mathrm{C}$ warming in the Indian Ocean. This warming is consistent and persistent over the 1950-present era, correlates strongly with global air temperature over the 1900-2009 era, and shows up as a pronounced "hockey stick" in related proxy data (coral and station air temperature data). It is also uniformly reproduced by all the IPCC climate models and several different precipitation time series (Williams and Funk, 2011) including the Global Precipitation Climatology Project (Adler et al., 2003), NCEP-DOE Reanalysis 2 (NCEP II, Kanamitsu et al., 2002), CPC Merged Analysis of Precipitation (Xie and Arkin, 1997), CPC Precipitation Reconstruction (Chen et al., 2003), and NOAA merged precipitation reconstruction (Smith et al., 2010). Both Indian Ocean sea surface temperatures and Kenyan, Ethiopian, and Sudanese rainfall and temperature trends exhibit considerable levels of persistence on decadal time scales. Thus, even in the absence of greenhouse gas forcings, momentum in the climate system seems likely to cause these trends to persist for at least the next 10-15 years. 


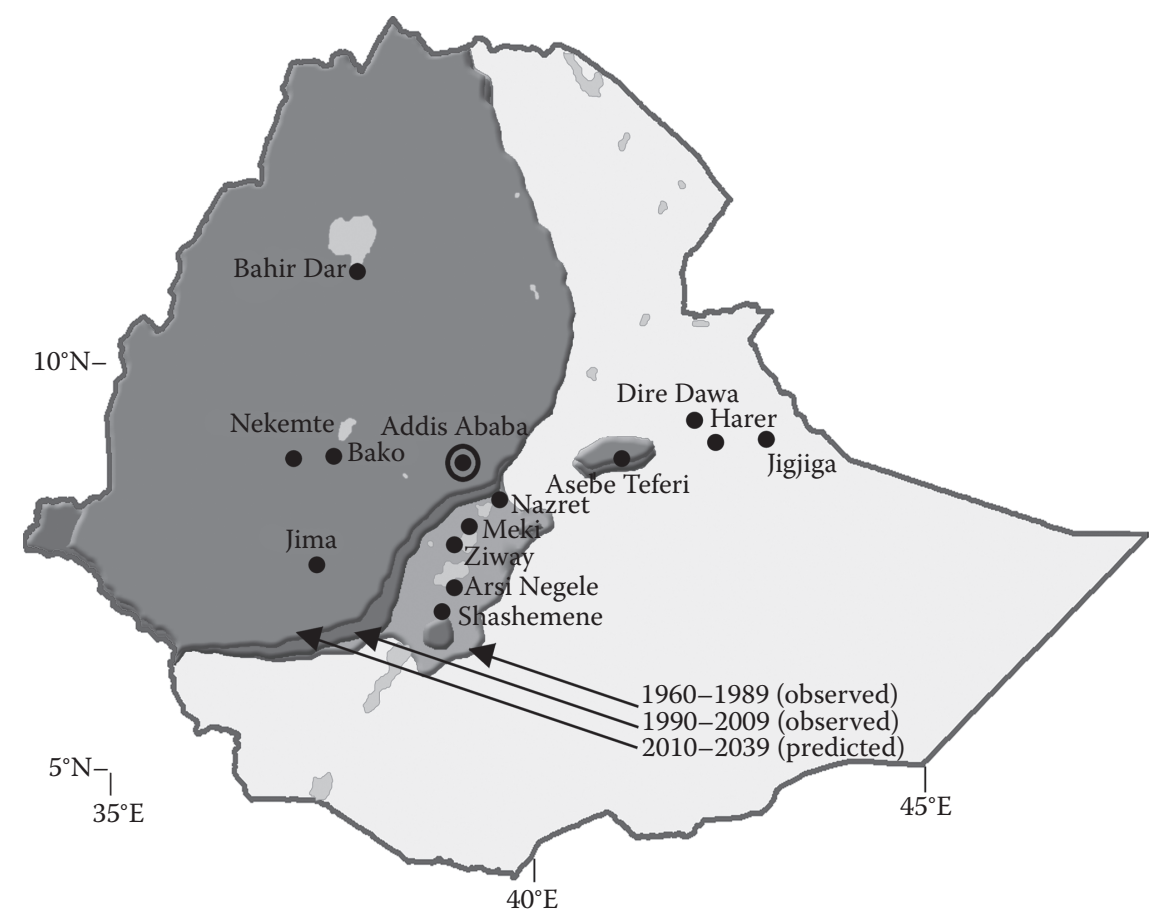

FIGURE 14.8 Change in suitable crop growing areas in south-central Ethiopia. The three overlain polygons show areas typically receiving enough rain to support a healthy crop (areas receiving, on average, more than $500 \mathrm{~mm}$ of JJAS rainfall), during 1960-1989, 1990-2009, and 2010-2039.

Figure 14.8 shows an example graphic for the main Ethiopian growing season (JJAS). The purpose of this graphic is to convey how increasingly frequent droughts may impact the area and location of prime crop growing areas. This transition over time is shown as the expansion or dilation of an isohyet, chosen to demarcate reasonably productive crop growing areas. In the example shown here, the $500 \mathrm{~mm}$ contour line was chosen, based on crop water demands and maps of productive crop growing areas (not shown). In Figure 14.8, the bottom (light brown) polygon depicts areas that, on average over 1960-1989, received enough rain to support a healthy crop (more than $500 \mathrm{~mm}$ of JJAS rainfall). The dark brown (middle) polygon shows the region that, on average, received more than 500 mm over 1990-2009. The combination of these two polygons, therefore, identifies where the rain gauge observations have exhibited a significant retreat in rainfall between 1960 and 2009, exposing the heavily farmed and populated area south of Addis Ababa to more frequent crop failures. This change in rainfall places increased climatic pressures on the precarious agricultural and pastoral livelihoods in this region. The orange (top) polygon shows the anticipated location of the $500 \mathrm{~mm}$ isohyets over the 2010-2039 time period. This contour line is produced by assuming a persistence of the local rate of change of rainfall (Figure 14.7). Interestingly, the retreat of the isohyets slows because of the steep topographic rainfall gradients (Figure 14.5). This map, thus, has two important 
adaptation messages. First, a large number ( 16 million) of people in food-insecure southern Ethiopia have experienced lower rainfall and a greater number of drought events (Seleshi and Zanke, 2004). Second, the mountainous western half of the country is protected by the steep rainfall gradients, and the higher elevation rainfall is anticipated to be less negatively impacted. Efforts focused on increasing crop production in these moist regions are likely to be more successful, given the regions' much lower incidence of drought.

\subsection{CONCLUSIONS}

The study presented here demonstrates the contribution that satellite observations can make to traditional climate mapping applications. Although satellites provide indirect estimates of air temperature or rainfall, they have a tremendous ability to discriminate spatial gradients, distinguishing warm from cold and wet from dry. Rather than focus on satellites' representation of day-to-day variations, this work leverages correlations between satellite observations and in situ observations to produce high-quality maps of mean rainfall and temperature fields and trends. Because satellite fields relate directly to climate observations, they typically exhibit strong local correlations (as shown in Figure 14.4 and Table 14.2), with mean fields using these data as predictors being highly accurate (Table 14.3). This study found that satellite predictors also improved the accuracy of trend interpolations, and the inclusion of satellite data provided more accurate interpolation surfaces and the associated lower standard errors reduced spatial signal-to-noise ratios. Drought occurs at many temporal scales, and low frequency changes can be the hardest to map accurately; satellite data can help us map and mitigate these slowest of slow-onset disasters. This allows for confident assertions to be made over areas even where the density of observations is quite low. Accurate depictions of the mean climate and climate trends are important because they support the targeted identification of at-risk populations and a spatially aware approach to designing adaptation and development strategies. Our results suggest that the ever-increasing satellite record can contribute to these objectives by providing precise, spatially dense, and physically meaningful observations of climatic gradients.

Whether anthropogenic or caused by internal climate variations, monitoring and understanding recent low frequency climate changes will be a vital challenge for the twenty-first century. Demands for water and food will increase, while the earth's capacity to provide will remain relatively fixed. Effective climate observing systems will be one of the first lines of defense against climate shocks, and satellite systems can play a critical role. One bête noire, however, that has always plagued the satellite world has been the occurrence of temporal nonhomogeneities in the satellite record. Changes in platforms, sensors, and flight paths have all made piecing together a sterling record a difficult but worthy challenge. Although not suitable to all purposes, or intended as a replacement for a homogenous satellite record, the FCLIM and FTA methodology presented here leverages the tremendous wealth of the satellite record without being reliant on the satellites themselves for detecting trends. As population pressure and economic growth increase demands for water and food, the ability of satellites to accurately observe gradients of precipitation and temperature will help us to better map and manage our natural resources. 


\section{REFERENCES}

Adler, R.F., J. Susskind, G.J. Huffman, A. Chang, R. Ferraro, P.-P. Xie, J. Janowiak, B. Rudolf, U. Schneider, S. Curtis, D. Bolvin, A. Gruber, J. Susskind, P. Arkin, and E. Nelkin. 2003. The version-2 global precipitation climatology project (GPCP) monthly precipitation analysis (1979-present). Journal of Hydrometeorology 4:1147-1167.

Brown, M.E. and C. Funk. 2008. Food security under climate change. Science 319:580-581.

Chen, M., P. Xie, J.E. Janowiak, P.A. Arkin, and T.M. Smith. 2003. Reconstruction of the oceanic precipitation from 1948 to the present. AMS 14th Symposium on Global Change and Climate Variations, Long Beach, CA. Boston, MA: American Meteorological Society.

Funk, C., A. Asfaw, P. Steffen, G. Senay, J. Rowland, and J. Verdin. 2003a. Estimating Meher crop production using rainfall in the 'Long Cycle' region of Ethiopia. FEWS NET Special Report. http://reliefweb.int/sites/reliefweb.int/files/resources/9EC256793FA16 85C49256DB90003E3DC-fews-eth-06oct2.pdf (accessed on January 29, 2012).

Funk, C. and M. Brown. 2005. A maximum-to-minimum technique for making projections of NDVI in semi-arid Africa for food security early warning. Remote Sensing of Environment 101:249-256.

Funk, C. and M. Brown. 2009. Declining global per capita agricultural capacity production and warming oceans threaten food security. Food Security 1(3):271-289.

Funk, C., M. Dettinger, J.C. Michaelsen, J.P. Verdin, M.E. Brown, M. Barlow, and A. Hoell. 2008. Warming of the Indian Ocean threatens eastern and southern African food security but could be mitigated by agricultural development. Proceedings of the National Academy 105:11081-11086.

Funk, C., G. Husak, J. Michaelsen, T. Love, and D. Pedreros. 2007. Third generation rainfall climatologies: Satellite rainfall and topography provide a basis for smart interpolation. Crop and Rangeland Monitoring Workshop, Nairobi, Kenya, Extended Abstract. http://earlywarning.usgs.gov/fews/pubs/RecentDroughtTendenciesInEthiopia.pdf (accessed on January 29, 2012).

Funk, C. and J. Michaelsen. 2004. A simplified diagnostic model of orographic rainfall for enhancing satellite-based rainfall estimates in data poor regions. Journal of Applied Meteorology 43:1366-1378.

Funk, C., J. Michaelsen, J. Verdin, G. Artan, G. Husak, G. Senay, H. Gadain, and T. Magadzire. 2003b. The collaborative historical African rainfall model: Description and evaluation. International Journal of Climatology 23:47-66.

Funk, C., G. Senay, A. Asfaw, J. Verdin, J. Rowland, J. Michaelsen, G. Eilerts, D. Korecha, and R. Choularton. 2005. Recent drought tendencies in Ethiopia and equatorial-subtropical eastern Africa. FEWS NET Special Report. http://earlywarning.usgs.gov/fews/pubs/ RecentDroughtTendenciesInEthiopia.pdf (accessed on January 29, 2012).

Funk, C. and J. Verdin. 2009. Real-time decision support systems: The Famine Early Warning System Network (Chapter 17). In Satellite Rainfall Applications for Surface Hydrology, G. MeKonnen and F. Hossain (eds.), New York: Springer-Verlag.

Janowiak, J.E., R.J. Joyce, and Y. Yarosh. 2001. A real-time global half-hourly pixel-resolution infrared dataset and its applications. Bulletin of the American Meteorological Society 82:205-217.

Kanamitsu, M., W. Ebisuzaki, J. Woollen, S.K. Yang, J.J. Hnilo, M. Fiorino, and G.L. Potter. 2002. NCEP-DOE AMIP-II reanalysis (R-2). Bulletin of the American Meteorology Society 83:1631-1643.

New, M., M. Hulme, and P.D. Jones. 1999. Representing twentieth century space-time climate variability. Part 1: Development of a 1961-90 mean monthly terrestrial climatology. Journal of Climate 12:829-856. 
New, M., M. Hulme, and P.D. Jones. 2000. Representing twentieth century space-time climate variability. Part 2: Development of 1901-96 monthly grids of terrestrial surface climate. Journal of Climate 13:2217-2238.

Seleshi, Y. and U. Zanke. 2004. Recent changes in rainfall and rainy days in Ethiopia. International Journal of Climatology 24(8):973-983.

Smith, T.M., P.A. Arkin, M.R.P. Sapiano, and C.-Y. Chang. 2010. Merged statistical analyses of historical monthly precipitation anomalies beginning 1900. Journal of Climate 23:5755-5770.

Verdin, J., C. Funk, G. Senay, and R. Choularton. 2005. Climate science and famine early warning. Philosophical Transactions of the Royal Society Biological Sciences 360(1463):2155-2168.

Verdin, K.L. and S.K. Greenlee. 1996. Development of continental scale digital elevation models and extraction of hydrographic features. Proceedings: Third International Conference on Integrating GIS and Environmental Modeling, Santa Fe, NM.

Wan, Z. and J. Dozier. 1989. Land-surface temperature measurement from space: Physical principles and inverse modeling. IEEE Transactions on Geoscience and Remote Sensing 27(3):268-278.

Williams, P. and C. Funk. 2011. A westward extension of the warm pool leads to a westward extension of the Walker circulation, drying Eastern Africa. Climate Dynamics (DOI: 10.1007/s00382-010-0984-y).

Xie, P. and P.A. Arkin. 1997. A 17-year monthly analysis based on gauge observations, satellite estimates, and numerical model outputs. Bulletin of the American Meteorological Society 78(11):2539-2558. 

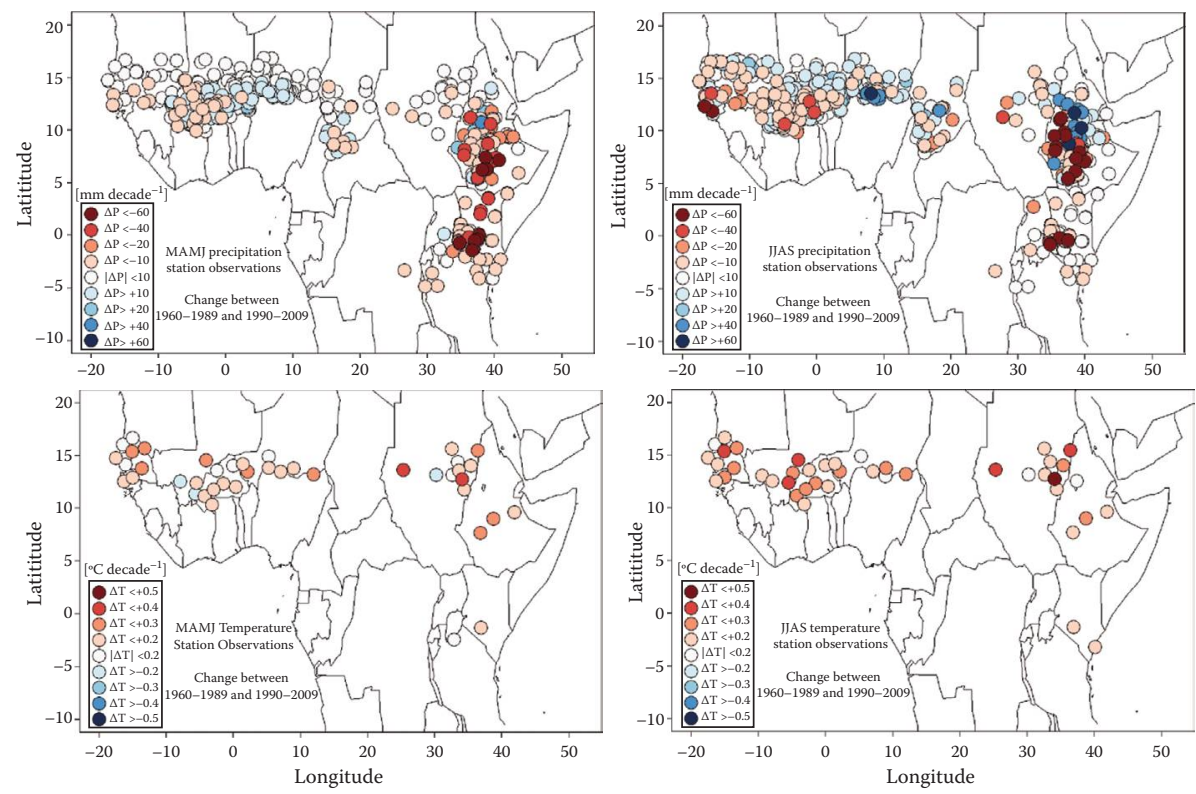

FIGURE 14.2 Station observations of rainfall change (top) and temperature change (bottom) between the 1960-1989 average and the 2000-2009 average for MAMJ (left) and JJAS (right). 

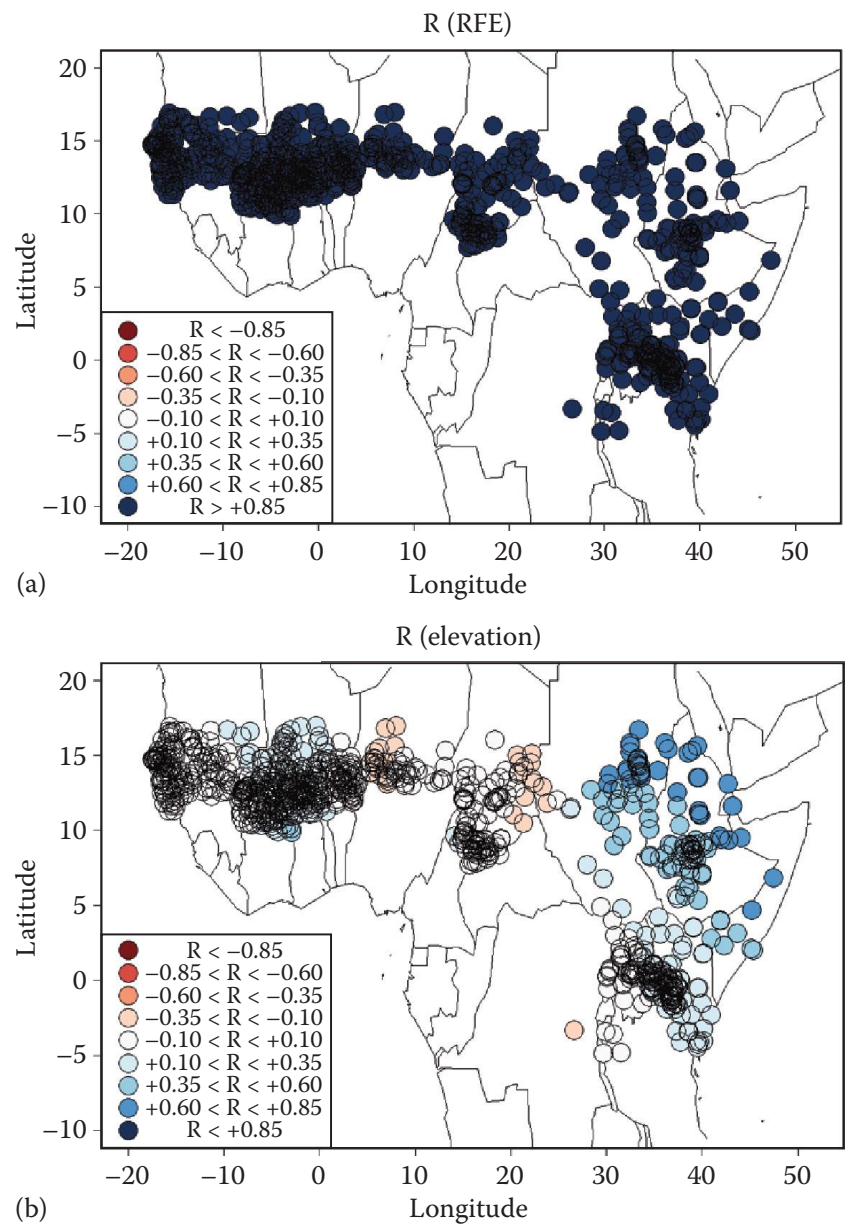

FIGURE 14.4 Comparison of RFE2 and elevation correlations with JJAS precipitation normals showing the local correlation between station observations of JJAS rainfall and RFE2 means (a) and elevation (b). The median local correlation between the station means and RFE2 means was 0.91 . Local correlation computations are based on a $d_{\max }$ value of $1500 \mathrm{~km}^{2}$. 

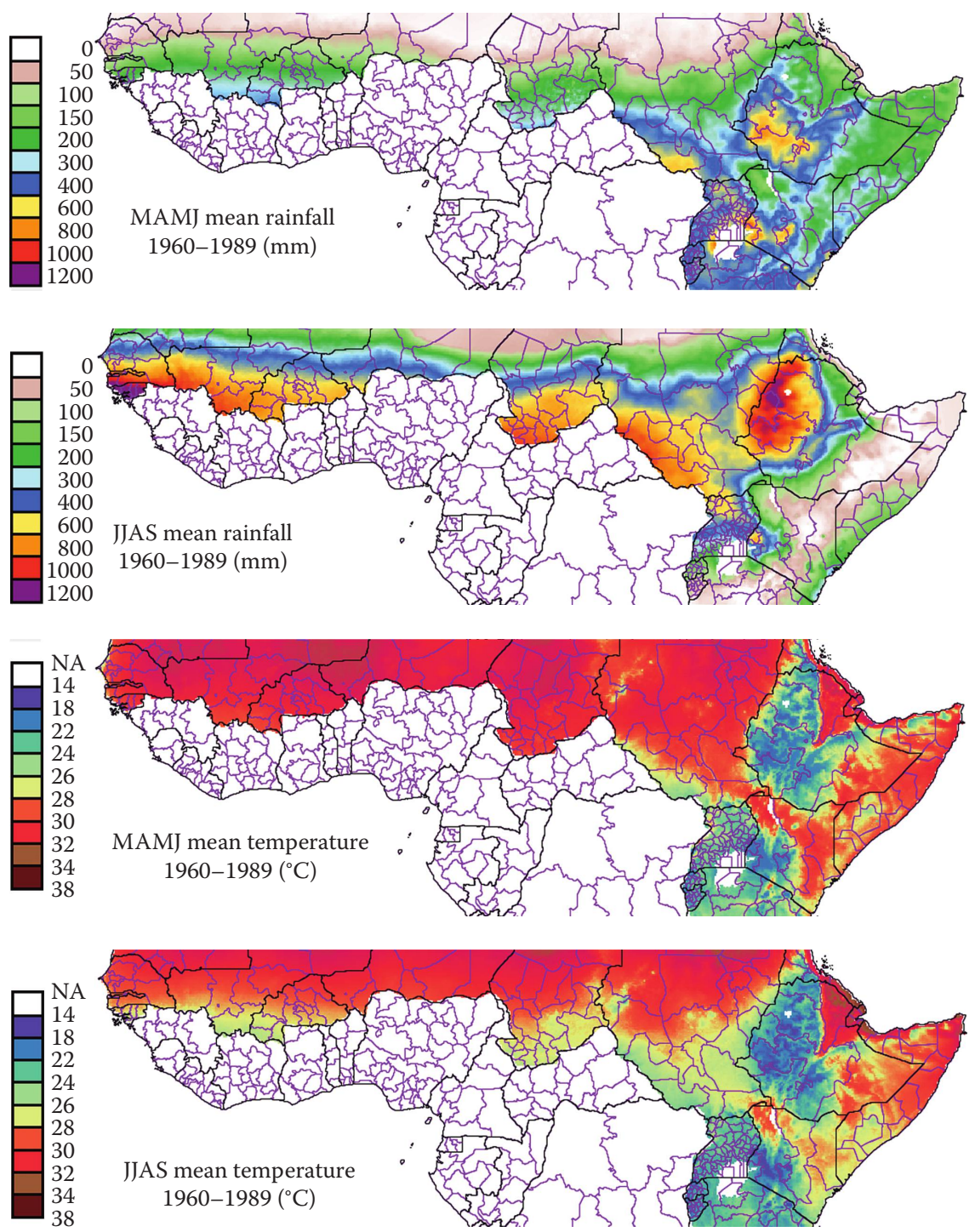

FIGURE 14.5 FCLIM maps for average 1960-1989 seasonal rainfall and air temperature for the MAMJ and JJAS seasons. 

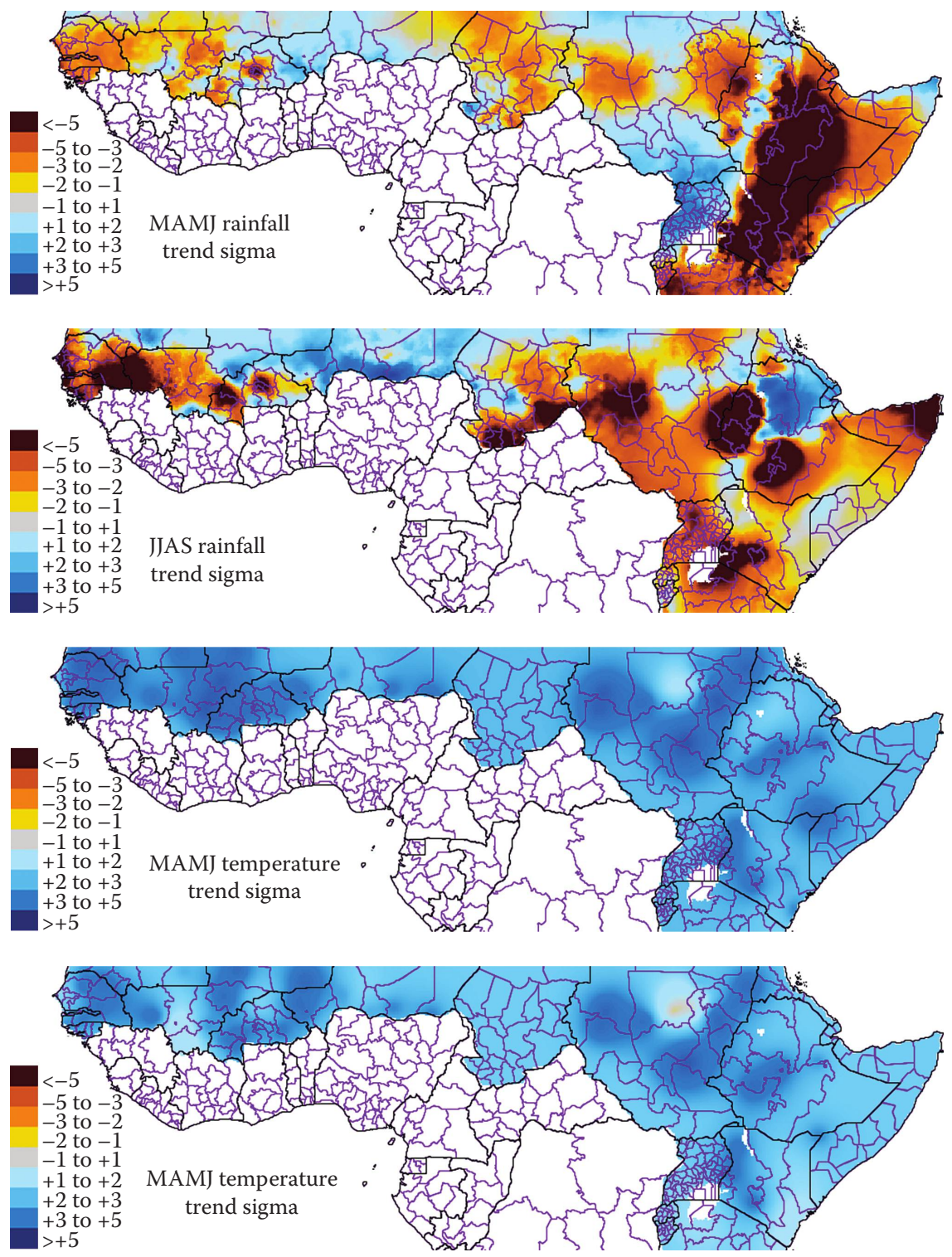

FIGURE 14.6 Rainfall and temperature sigma fields. Sigma values are the estimated trend fields divided by the interpolation standard error. 

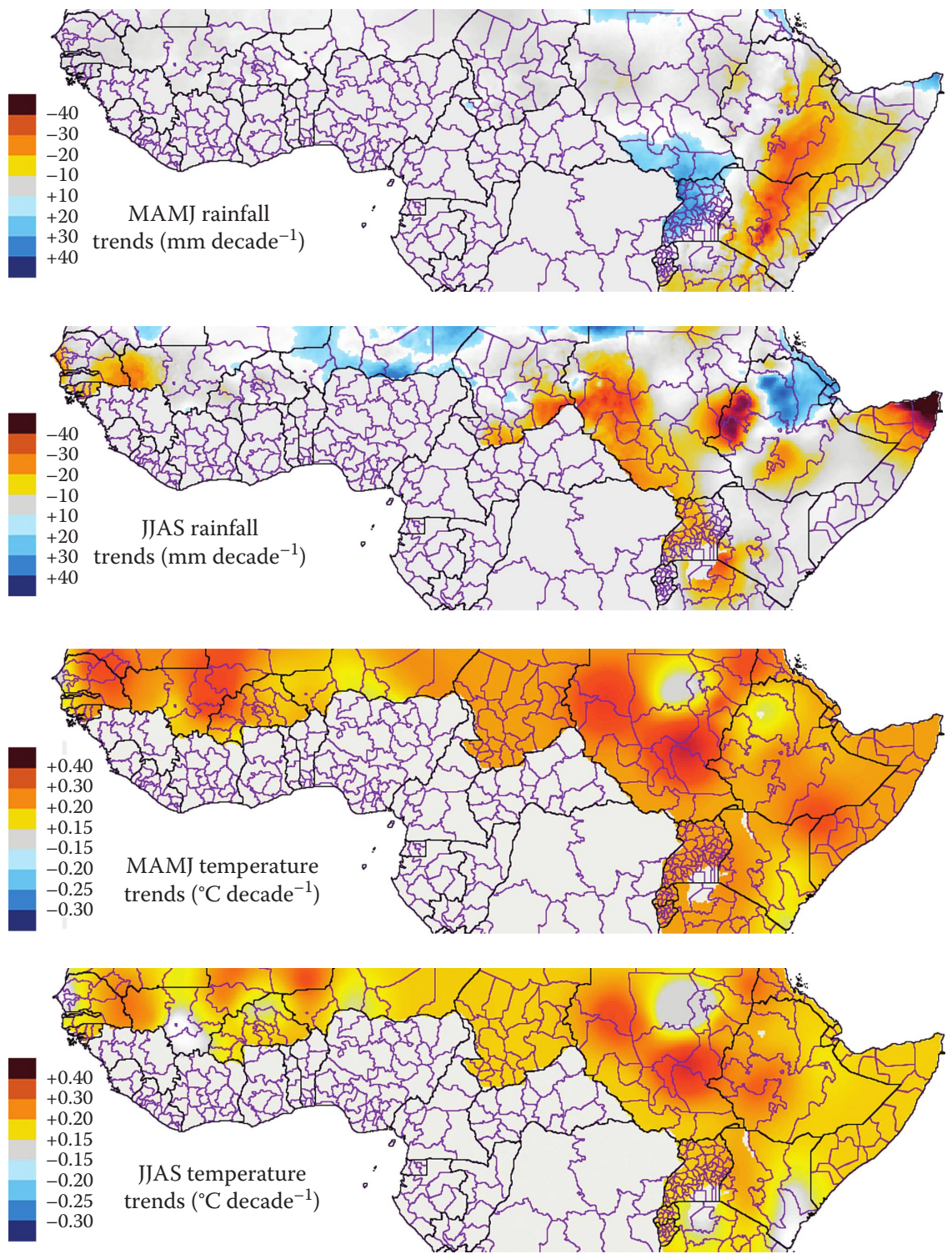

FIGURE 14.7 The 1960-2009 rainfall and trend maps for MAMJ and JJAS. 